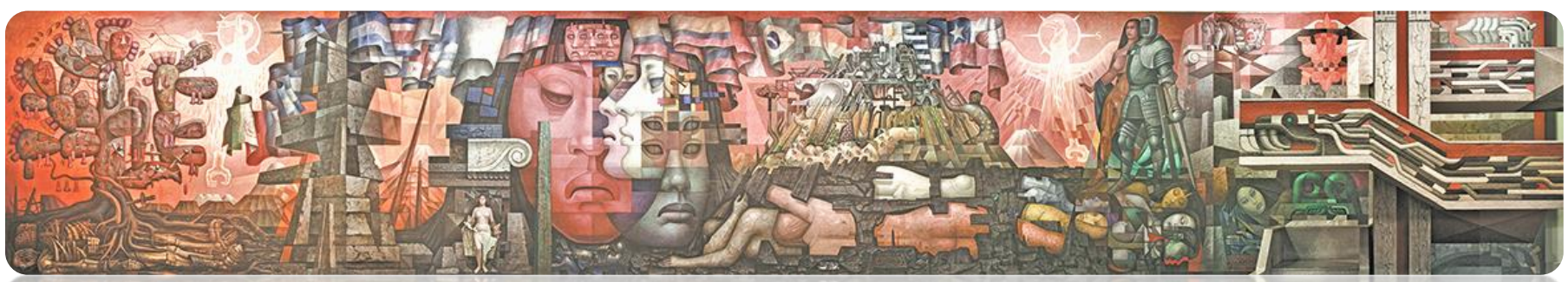

Rev. Hist., N²8, vol. 2, Julio-Diciembre 2021: 294-333

ISSN 0717-8832

https://doi.org/10.29393/RH28-35RSRS10035

\title{
Relaciones sociales y desplazamiento forzado en el fundo Puñir-Releco. De las prácticas paternalistas a la imposición neoliberal en la cordillera valdiviana, 1947-1994*
}

Social relations and forced displacement in the Puñir-Releco farm. From paternalistic practices to neoliberal imposition. Valdivian mountain range, 1947-1994

Robinson Silva Hidalgo**

\section{RESUMEN}

El fundo Puñir-Releco amplió el proceso industrializador de tipo forestal en la Provincia de Valdivia. Nuestro objetivo es comprender el proceso de ocupación del fundo desde su instalación con prácticas paternalistas, pasando por el control obrero de la actividad y hasta su disolución producto de la instalación neoliberal. A través de documentación radicada en ARNAD, ODEPLAN y testimonios de antiguos habitantes del fundo, concluimos que las relaciones sociales se conformaron en un régimen de prácticas paternalistas que devino en una comunidad obrera que se sumó al proyecto socialista. Con la dictadura y el neoliberalismo no se volvió al viejo régimen, se fundó un nuevo tipo de relaciones sociales.

Palabras clave: Puñir-Releco, Cofomap, industria forestal, prácticas paternalistas, Valdivia, relaciones sociales.

\footnotetext{
* Este artículo es parte del trabajo del Núcleo interdisciplinario UACh Desigualdad y Derechos Humanos. A su vez se inserta en el proyecto Anillos: "Patrimonio Industrial: Formas de habitar colectivo en el sur de Chile. Aportes para su puesta en valor y recuperación integrada" financiado por el Programa de Investigación Asociativa PIA-Conicyt SOC1403. Agradecimientos a los ayudantes Nicole Godoy e Iván Mella.

** Doctor en Historia. Docente del Instituto de Historia y Ciencias Sociales de la Universidad Austral de Chile-Valdivia. ORCID: https://orcid.org/0000-0003-0175-2194.Correo electrónico: robinson.silva@uach.cl
} 


\section{ABSTRACT}

The Puñir-Releco farm expanded the forest-type industrialization process in the Province of Valdivia. Our objective is to understand the process of occupation of the farm from its installation with paternalistic practices, through workers' control of the activity and until its dissolution as a result of the neoliberal installation. Through documentation located in ARNAD, ODEPLAN and testimonies of former inhabitants of the farm, we conclude that social relations were formed in a regime of paternalistic practices that became a working-class community that joined the socialist project, with the dictatorship and neoliberalism did not revert to the old regime, a new type of social relations was founded.

Keywords: Puñir-Releco, Cofomap, forestry industry, paternalistic practices, Valdivia, social relations.

Recibido: diciembre 2021

Aceptado: marzo 2021

\section{Introducción}

La apropiación privada del territorio cordillerano de Valdivia tiene sus inicios a fines del siglo XIX y principios del XX. Las áreas a las que hacemos mención fueron ocupadas por empresarios nacionales y extranjeros ${ }^{1}$ y -amparados por la legislación- fueron arrebatando tierras a comunidades mapuches e instalando, poco a poco, su preeminencia con la finalidad de explotar los ricos bosques de raulíes. Este fue un esfuerzo empresarial con el apoyo del Estado chileno. De esta forma, la propiedad privada se impuso, cambiando para siempre el estatus de la zona hacia la década del treinta ${ }^{2}$. Ya hacia los años cuarenta los aserraderos y explotaciones forestales estaban presentes en el vasto territorio y, con ello, el llamado a la mano de obra fue inmediato y requisito esencial para levantar esas duras faenas. Como se refiere en investigaciones recientes, el proceso conllevó la organización sindical y las primeras acciones de movilización de los trabajadores:

"Las condiciones precarias en que se desarrollaba la vida del obrero forestal, la falta de dinero y el aislamiento, motivan tomas y huelgas. En el fundo Carranco, cercano a Neltume, se produjeron tomas en los años 1944 y 1953, las que fueron violentamente reprimidas por la policía (CODEPU 1991). En 1951, los trabajadores de la Fábrica Neltume, exigiendo

\footnotetext{
${ }^{1}$ Bernedo, Patricio. 1996. Panguipulli. Historia de cuatro tiempos, Santiago, s/editorial.

2 Barrena, José, et. al. 2016. "Antecedentes históricos del Complejo Forestal y Maderero Panguipulli, provincia de Valdivia, centro sur de Chile", en Bosque Vol.37, №3, p. 476. Los autores mencionan claramente el decreto supremo $\mathrm{N}^{\circ} 4363$ de 1931, como la acción afirmativa del apoyo estatal a la explotación forestal en marcha en el territorio.
} 
mejores condiciones habitacionales y laborales, levantando una huelga que duró tres meses". ${ }^{3}$

De esta manera, precedidos por intensos procesos de conflicto con los dueños de fundos y aserraderos, mediante huelgas y tomas, los pobladores fueron dando una intensa vida social a los diferentes asentamientos que, poco a poco, se fueron transformando en localidades que derivaron en precarios pueblos de montaña. Esta situación se provocó: "A pesar de las condiciones de marginación social, laboral política dentro de los obreros, que lentamente va motivando intentos de organización sindical que en 1951 originan una movilización, que fue violentamente reprimida". ${ }^{4}$ De esta manera, la poca cobertura de servicios sociales y falta de políticas públicas produjo comunidades cada vez más demandantes y dispuestas a la movilización.

En particular, centramos nuestro interés en el tipo de relaciones sociales que se desarrollaron en la zona, ayudados por la literatura acerca del paternalismo y sus prácticas. Definimos las formas de habitar como la constitución material de determinadas relaciones sociales, porque existen transformaciones importantes de los sujetos que impulsan los procesos económicos y sociales. Marx señala que "no es por cierto una diferencia formal, sino que supone un trastocamiento total del modo mismo de producción" ${ }^{\prime 2}$. Esos cambios indican la existencia de regímenes que explotan un determinado espacio en un tiempo histórico específico, siguiendo a Wallerstein. ${ }^{6}$

Efectivamente, las formas de proletarización se fueron asentando con las características propias del siglo XX. El poblamiento de los distintos fundos se produjo a través de diversas migraciones que, en un régimen de trabajo cercano al paternalismo industrial, es decir, trabajadores sometidos a un fuerte control de su tiempo y actividades por parte del patrón, ${ }^{7}$ fueron asentando los nuevos contingentes en torno a las explotaciones forestales y aserraderos que concentraron la actividad económica en la zona. Definimos este régimen como cercano al paternalismo industrial, porque no se refiere a un régimen paternalista propiamente tal según

\footnotetext{
3 Ídem.

${ }^{4}$ Rivas, Ricardo. 2006. Desarrollo forestal de Neltume: Estado y trabajadores (1924-1990). Tesis par optar al título de profesor de Historia, Geografía y Educación Cívica. Universidad Austral de Chile-Valdivia, p. 41. Se relatan las graves condiciones de vida, incluyendo la falta derechos sociales y la represión empresarial.

${ }^{5}$ Cursivas en el original. Marx, Karl. 1971. Elementos fundamentales para la crítica de la economía política (Borrador) 1857-1858, Tomo I, Madrid, Siglo XXI, p. 219.

${ }^{6}$ Wallerstein, Immanuel. 2014. El capitalismo histórico. Madrid, Siglo XXI. En este texto se da cuenta de las continuas transformaciones del capitalismo y cómo esto configura el sentido histórico de sus procesos.

${ }^{7}$ Sierra, José. 1990. El obrero soñado. Ensayo sobre el paternalismo industrial. Asturias (1860-1917), Madrid, Siglo XXI, pp. 36-69.
} 
lo descrito en la literatura al respecto; los elementos diferenciadores que presenta el fundo estudiado los explicaremos en el desarrollo de este texto.

Debido a lo anterior, definimos como prácticas paternalistas las existentes en el caso de estudio, por ello primero debemos aclarar qué significa el paternalismo industrial. Podemos referir algunas ideas que, en el último tiempo, han venido a esclarecer la existencia de este régimen de trabajo en las diferentes regiones del país. Los casos más conocidos y documentados están en el norte del país, en torno a la industria salitrera y minera en general. También en el Bío-Bío diversos casos de establecimientos industriales son referentes; los estudios se han multiplicado en el último tiempo, dando a conocer formas de habitar en la Patagonia y las regiones del centro sur en la que inscribimos este caso ${ }^{8}$.

En ese sentido, la mayor parte de los sectores considerados como paternalistas se encuentran en zonas urbanas, pero en el caso de la actividad maderera y forestal, también presentan instalaciones que podemos llamar campamentos, incluso pueblos constituidos en torno a alguna actividad productiva. En la zona referida es conocido el caso de Neltume:

"A partir de 1930 se instaló la empresa maderera en el territorio de la pre-cordillera valdiviana, en el término municipal de Panguipulli, con la finalidad de extraer la materia prima de los bosques nativos y de generar un punto de desarrollo forestal para la región y el país, conectando líneas férreas que permitieron su futura consolidación... El origen del conjunto se relaciona al auge maderero de la época, en donde la organización sindical de los trabajadores logró negociar las condiciones necesarias para que la empresa colabore con la construcción de las viviendas para los trabajadores y sus familias"

La situación del predio Puñir-Releco, así como otros tantos poblados forestales (Enco, Arquilhue, Pirihueico, etcétera), dan muestra de la expansión de la actividad forestal en la zona hacia la medianía del siglo $X X^{10}$. En un régimen que incluyó diversas formas de relaciones

\footnotetext{
8 Videla, Enzo, et. al. 2016. El orden fabril. Paternalismo industrial en la minería chilena 1900-1950, Valparaíso, América en Movimiento. Artaza, Pablo. 2018. La producción social del espacio salitrero tarapaqueño durante el ciclo de expansión: entre la necesidad patronal de control social y la resistencia de la sociedad pampina, en Tiempo histórico, $\mathrm{N}^{\circ}$ 17, Santiago, pp. 47-84. Venegas, Hernán y Morales, Diego. 2015. El despliegue del Paternalismo Industrial en la Compañía minera e industrial de Chile (1920-1940), en Historia Crítica, N 58, Bogotá, pp. 117-136. Brito, Alejandra. 2018. Memoria colectiva y construcción de territorio: auge y despojo de una cultura industrial. Los casos de la fábrica textil Bellavista-Tomé y la carbonífera Schwager en Coronel (1970-2007), Izquierdas, $\mathrm{N}^{\circ} 42$, Santiago, pp. 1-29. Acevedo, Pía y Rojas, Carlos. 2015. Enapinos. Los campamentos petroleros del fin del mundo. Santiago, El otro Kanon. Silva, Robinson. 2019. Una forma de habitar en clave modernizadora. El barrio Arica de Valdivia, 1948-1960. Sophia Austral, № 25, Punta Arenas, pp. 139-159.

${ }_{9}^{9}$ Brito, Alejandra et. al. 2018. Industria y habitar colectivo. Conjuntos habitacionales en el sur de Chile, Concepción, Stoq, p. 145.

${ }^{10}$ Silva, Robinson, et al. 2020. Memorias expulsadas de Enco. Reconstrucción histórica de los antiguos habitantes del fundo Enco y su demanda de recuperación territorial, Valdivia, edición digital.
} 
sociales de producción y fue dibujando un paisaje social que refirió prácticas paternalistas ${ }^{11}$ herederas de las modalidades ya conocidas en otros lugares del país: el encierro, la pulpería y el control sobre las formas de reproducción de la vida y la sociedad. Por otra parte, también existieron formas de trabajo temporal y actividades de contrato informal que dan un perfil menos claro que la clásica modalidad conocida en Chile y otros lugares de desarrollo capitalista industrial. Es decir, las prácticas paternalistas marcaron un régimen que heredó del paternalismo conocido en el primer siglo XX, pero que en este contexto solo conservó algunos de sus elementos, tensionado por nuevas formas de relaciones sociales de producción y de habitar, tal como veremos en adelante.

De esta forma, siguiendo a Alejandra Brito, consideramos las prácticas paternalistas como una categoría para explicar la especificidad del régimen de relaciones sociales existente en la zona: "Se trata de poner en interacción las prácticas y disposiciones de nivel micro-físico con las estrategias de poder más globales que operan en el ámbito de la población en tanto categoría sociodemográfica y factor neurálgico de la biopolítica. Esto es, las articulaciones entre saberes y poderes" ${ }^{\prime 2}$. En efecto, revisaremos esas prácticas en la lógica de sus saberes respecto al régimen que los controla, por ello nos centramos en el sentido de su habitar y los significados que adquieren para la comunidad.

Por otra parte, y avanzando en el proceso de desmantelamiento de las prácticas paternalistas, el punto esencial es cuándo se constituyó oficialmente el Complejo Forestal y Maderero Panguipulli (COFOMAP). Ello ocurrió cuando los diversos fundos forestales en manos de privados fueron siendo tomados por los trabajadores, ${ }^{13}$ en una intensa dinámica de lucha social que desembocó en la creación de una empresa estatal con un inusual control obrero y que se transformó en un paradigma para el proyecto socialista que el país vivía bajo la Unidad Popular ${ }^{14}$. De esta manera, El COFOMAP se puede considerar el punto álgido del proceso de explotación del territorio, marcando un momento de brillantez para la vida social y política de las familias habitantes de la zona; ahora bien, los 24 predios que definieron el área del COFOMAP pasaron a constituir una sola razón social, que incluyó a los fundos Puñir y Releco. Oficialmente, EI COFOMAP se articuló por fundos y predios expropiados mediante la Ley de Reforma Agraria 16.640 del 16 de julio de 1967. Sus socios fueron la Corporación de Fomento

\footnotetext{
11 Brito, Alejandra y Ganter, Rodrigo. 2015. Cuerpos habitados, espacios modelados: el caso de la siderúrgica Huachipato, 1940-1970. Historia 396, N 1, Viña del Mar, pp. 11-36. Este trabajo refiere como prácticas paternalistas las relaciones sociales presentes en establecimientos del sur de Chile, como el analizado aquí p. 17.

12 Brito. "Cuerpos habitados, espacios modelados". p. 14

${ }^{13}$ Morales, José Luis. 2020. Pan, tierra y socialismo. El MIR en la precordillera de Valdivia 1967-1973, Concepción, Escaparate, p. 59-61. Hubo sucesivas tomas de fundos en la provincia de Valdivia entre noviembre de 1970 y febrero de 1971.

${ }^{14}$ Bravo, José. 2012. De Carranco a Carrán, Las tomas que cambiaron la historia, Santiago, LOM. El texto relata las memorias de un protagonista del proceso constitutivo de la empresa estatal.
} 
(CORFO) y la Forestal Pilpilco ${ }^{15}$. La filial de CORFO fue sumando predios progresivamente hasta contabilizar los 24 . En todos ellos se realizaron fundamentalmente actividades forestales, pero también agrícolas y de servicios, que se desarrollaron en 420.000 hectáreas de su conformación definitiva.

En el desarrollo de la empresa es fundamental la gran efervescencia política que los trabajadores protagonizaron, corriendo cercos y organizando sindicatos que apoyaron decisivamente al gobierno de Salvador Allende, muchos de esos grupos y organizaciones obedecieron a la línea revolucionaria que planteó el MIR durante aquellos años. Esa línea definió que: “... la consigna del poder popular adquirió una dimensión estratégica, en cuanto cristalizó como una manifestación paralela al Estado burgués, asentado en las organizaciones y fuerzas sociales autónomas del proletariado y el pueblo"16. De esta manera, la cuerda política es relevante en la constitución de la empresa y su particular carácter:

"Se creó allí una empresa de Estado que tomó el nombre de Complejo Forestal de Panguipulli. A pesar de eso, ni el conflicto social ni el conflicto político llegaron a su término. Por un lado, los grandes propietarios impugnaron las expropiaciones y por otro los trabajadores, conducidos principalmente por el MIR consideraban que Panguipulli era el centro de una vasta región a movilizar políticamente y a reorganizar desde el punto de vista productivo. Es a partir de entonces que se produjo la primera entrada en acción del ejército de tierra en su función de gendarme social, iniciando actividades de inteligencia con la pretensión de neutralizar un espacio pasado bajo control del enemigo interno ${ }^{17}$.

Es interesante considerar, según señala Santana en la cita, que las actividades del COFOMAP se desarrollaron en medio de definiciones que no fueron conocidas ni sopesadas por los actores del proceso en su área de influencia. No es de extrañar -entonces- que, producido el golpe de Estado, esa presencia militar tuviera un triste protagonismo en la represión que azotó la zona, la que puede contar el trágico balance de más de 80 ejecuciones, entre otras violaciones a los derechos humanos ${ }^{18}$.

Efectivamente, en el inmenso territorio que constituía el Complejo, las fuerzas militares y represivas ocuparon los diversos fundos, aplicando castigos que terminaron en cientos de

\footnotetext{
${ }^{15}$ Archivo Nacional de la Administración [ en adelante ARNAD]. Fondo Complejo forestal y maderero [en adelante COFOMAP], 8 de enero de 1974. Breve síntesis del "Complejo Forestal y Maderero (COFOMAP LTDA)", Volumen 136. La escritura pública fue hecha ante el notario de Santiago Hernán Chadwick Valdés.

${ }^{16}$ Goicovic, Igor. 2016. Trabajadores al poder. El movimiento de izquierda revolucionaria (MIR) y el proyecto revolucionario en Chile 1965-1994. Concepción, Escaparate, p. 121. El rol del MIR es refrendado en esta línea por Palieraki, Eugenia. 2014. i La revolución ya viene! El MIR chileno en los años sesenta, Santiago, LOM, p. 279.

17 Santana, Roberto. Control del espacio y control social en el Estado militar chileno, en Revista de Geografía Espacios, vol. 3, N 6, Santiago, p. 23.

${ }^{18}$ CODEPU. 1991. Chile, recuerdos de la guerra. Valdivia, Neltume, Chihuío, Liquiñe, Santiago, Emisión, p. 43-152.
} 
víctimas, muchas de ellas ejecuciones, pero también desapariciones, tortura, exilio, prisión política y desplazamiento forzado. Esta violencia de Estado que, con alguna gradualidad, se padeció durante toda la dictadura, tuvo procedimientos tan diversos como crueles:

"En Neltume y Chihuío hay restos de ejecutados: en el primer caso porque fueron ejecutados en Valdivia mediante juicios de guerra ilegales; en Chihuío, porque a raíz de los testimonios de familiares y testigos de las desapariciones se han encontrado restos de los ejecutados en fosas comunes trasladadas varias veces de un lugar a otro. En Liquiñe, en cambio, los cuerpos fueron arrojados al río y hasta hoy se encuentran desaparecidos" ${ }^{19}$.

Como decíamos, el golpe de Estado del 11 de septiembre de 1973 trajo importantes cambios para el territorio donde se asentó COFOMAP, empresa que sufrió un violento cambio en sus actividades y formas de gestión, desapareciendo el Consejo de Administración, algunos asesinados y otros detenidos y exiliados. Todo el territorio de influencia del COFOMAP pasó a administración de la CONAF y luego a la agencia que creó la empresa, CORFO. Con posterioridad y ya en la década de los ochenta, se procedió a la privatización de los diferentes fundos, desmantelando la actividad de los aserraderos, cuestión que se enmarca en el proceso de desindustrialización que es característico del modelo neoliberal impuesto por la dictadura ${ }^{20}$.

Hacia la segunda mitad de los ochenta, la empresa comenzó a ser liquidada, mediante diversas convocatorias se fueron privatizando los predios, las antiguas unidades fueron siendo traspasadas a nuevos propietarios, nuevos dueños prácticamente desconocidos en la zona. Es decir, casi ningún predio volvió a sus antiguos dueños. Por otra parte, también aparecieron procesos de capitalismo popular, como se le denominó a la constitución de sociedades anónimas conformadas por trabajadores de la empresa y que aportaban para ser socios accionarios de una nueva razón social ${ }^{21}$.

Junto con ello, las autoridades dictatoriales tuvieron una actitud de fuerte persecución para con los trabajadores y habitantes del sector cordillerano, esto con el objetivo de expulsarlos de sus casas y trabajos, a través de diversos mecanismos, esta política de despojo fue sistemática hasta el término del COFOMAP. Esta figura conocida como desplazamiento forzado, es

\footnotetext{
${ }^{19}$ Barrientos, Claudio. 2003. "Y las enormes trilladoras vinieron (...) a llevarse la calma": Neltume, Liquiñe y Chihuío, tres escenarios de la construcción cultural de la memoria y la violencia en el sur de Chile, en Del Pino, Ponciano. y Jelin, Elizabeth. (comps.) Luchas locales, comunidades e identidades, Madrid, Siglo XXI, p. 109.

${ }^{20}$ Gárate, Manuel. 2012. La revolución capitalista de Chile (1973-2003). Santiago: Ediciones Universidad Alberto Hurtado, pp. 308-306 estas privatizaciones se enmarcan en la denominada segunda ola privatizadora. Por otra parte, Valdivia, Verónica. 2003. El golpe después del golpe. Leigh vs. Pinochet. Chile 1960-1980. Santiago, LOM, pp. 172-192 explica el fallido proyecto de los militares que quisieron mantener el carácter social en dictadura, cuestión que cedió al imponerse el neoliberalismo.

${ }^{21}$ Cofré, Víctor. 2019. Ponce Lerou. Pinochet. El litio. Las cascadas. Las platas políticas. Santiago, Catalonia, pp. $75-$ 88.
} 
reconocida como un delito de lesa humanidad poco o nada estudiado en Chile. Pedro Cardyn, histórico militante y habitante del territorio, así señaló lo indicado por la autoridad: "Tienes una semana para desarmar tu rancha y cargar tus tablas y planchas de zinc en un camión que te dejará en Panguipulli o en sus alrededores ${ }^{22}$.

Así, el régimen de facto se instaló mediante el terrorismo de Estado y las políticas neoliberales para alterar las relaciones sociales de producción, generando altos niveles de pobreza, desempleo y despojo en los diversos predios del COFOMAP. Esto provocó un importante cambio en la forma en que las comunidades fueron viviendo prácticas marcadas por la imposición del régimen, como por ejemplo la ejecución de operativos cívico-militares en la zona: "fue un elemento esencial en la estrategia de la acción represiva de carácter militar en el área de conflicto. Su implementación revela el sentido claramente político de esa intervención mostrada como la cara amable de un proceso mucho más complejo" ${ }^{23}$.

Así, los predios que pertenecieron al COFOMAP acabaron en propiedad de diferentes grupos empresariales y personas. Hoy en día, toda el área comprendida por la antigua empresa estatal de control obrero está configurada por diversos programas de explotación, siendo la forestación una de ellas, pero también la ganadería, el negocio inmobiliario y los servicios turísticos. Efectivamente, las nuevas estrategias neoliberales aportaron al proceso de desmantelamiento económico sufrido por el territorio ${ }^{24}$.

Tanto el proceso represivo, en todas sus formas, como el desmantelamiento económico provocó que muchas familias y trabajadores fueran expulsados o simplemente abandonaran sus lugares de residencia ${ }^{25}$. Hasta entrados los noventa este proceso no paró, generando el despoblamiento de esta vasta área cordillerana. Este fenómeno nos habla, por una parte, de la nueva economía neoliberal, mientras el territorio comenzó a transformarse, pero no volviendo a las viejas prácticas paternalistas, sino activando formas de desposesión que hizo mutar las relaciones sociales, tal como lo indica Alfaro:

\footnotetext{
22 Cardyn, Pedro. 2017. Sangre de baguales. Epopeyas mapuches y obreras en tiempos del Complejo Maderero Panguipulli. Un efecto mariposa inconcluso. Santiago, LOM, p. 79.

${ }^{23}$ Silva, Robinson. 2015. Territorio en disputa: Guerrilla, represión y operativos cívico-militares en la precordillera valdiviana, Chile, 1981, en Boletín Americanista, año LXV, № 71, Vol.2, Barcelona, p. 209. En 1981 se realizaron sendos operativos cívico-militares en la zona, disputando el territorio a la guerrilla mirista que intentaba instalarse allí.

${ }^{24}$ De Matheus, Luis, et. al. 2018. El negocio de la conservación ambiental: cómo la naturaleza se ha convertido en una nueva estrategia de acumulación capitalista en la zona andino-lacustre de Los Ríos, sur de Chile, en Scripta Nova: revista electrónica de geografía y ciencias sociales, 22(583), Barcelona.

25 Harvey, David. 2007. Breve historia del neoliberalismo, Madrid, Akal. El autor manifiesta las formas que el neoliberalismo adquiere en cuanto su poder de apropiación del valor generado por los trabajadores, incluso cuando estos son despojados de toda participación en las ganancias.
} 
“El despojo de la tenencia de tierra y su privatización configura un paisaje rural donde los ex trabajadores del COFOMAP, van habitando las poblaciones pobres de los pueblos y de las ciudades intermedias, que serán denominados en la política oficial como villorrios agrícolas. Estos se transformaron en la práctica en campamentos de mano de obra temporal, capaz de adaptarse a las nuevas condiciones del trabajo precario bajo el neoliberalismo. A sus habitantes sólo les queda la opción de sobrevivir transitando por labores de distinta índole, asumiendo estrategias adaptativas de empleo..."26.

En este sentido, las relaciones sociales de producción -concepto amplio que nos ayuda a dibujar los diversos aspectos del conflicto entre capital y trabajo, expresadas en sus formas materiales específicas-, propias de la etapa neoliberal, están marcadas por la precarización del trabajo, la violación de los derechos fundamentales de los habitantes, el despojo físico de los medios de vida de la población y la concentración de la propiedad con nuevos negocios asociados al capital financiero y especulativo ${ }^{27}$.

Visto lo anterior, ello nos lleva a definir una hipótesis de trabajo: planteamos que el régimen de prácticas paternalistas fue fundamental en la conformación y la expansión de la industria forestal, situación que generó un grupo cohesionado de trabajadores forestales que se manifestó en una consciencia de clase expresada en la experiencia del COFOMAP y su devenir. Llegados a ese punto, el proceso represivo de instalación neoliberal no volvió a las viejas prácticas paternalistas, por el contrario, fundó nuevas relaciones sociales, de corte neoliberal que, entre otros efectos, despojaron a la población del área.

De esta manera, el objetivo general que buscamos alcanzar guarda relación con caracterizar y comprender el proceso de ocupación del fundo Puñir-Releco desde su instalación con prácticas paternalistas, pasando por el intento de control obrero de la actividad forestal y hasta su disolución producto de la instalación neoliberal en la zona.

Como enfoque historiográfico, este estudio se realiza desde la historia social del territorio, acentuando el rol de la construcción social del mismo por la generación de relaciones sociales de producción entre los diversos sujetos que actúan en el proceso. Nos acercamos a este tipo de enfoque de historia social, pues ayuda a configurar la materialidad con la que construimos el relato histórico. A partir de sus vestigios vamos encontrando las huellas de su pasado y el de las comunidades que hicieron posible que se construyera una forma de habitar y de vivir ${ }^{28}$. En ese sentido, la historia local aparece como un enfoque posible, pero preferimos llamarla

\footnotetext{
${ }^{26}$ Alfaro, Karen. 2016. "Acumulación por desposesión en Chile: el caso del Complejo Forestal y Maderero Panguipulli en el sur de Chile (1973-1990)". Historia 396, № 2, Viña del Mar, pp. 251-252.

27 Gárate, Manuel. 2012. La revolución capitalista, pp. 391-400 establece la manera concreta en que el neoliberalismo se comprende en el Chile de los ochenta y noventa.

28 Lefebvre Henri. 2013. La producción del espacio, Madrid, Capitán Swing.
} 
historia social descentrada dadas las implicancias ideológicas que dialogan con procesos generales vividos en un tiempo histórico específico, en la línea señalada por Illanes ${ }^{29}$.

Respecto a la metodología empleada, recurrimos a documentación de CORFO-COFOMAP depositada en el archivo de la administración (ARNAD), en ODEPLAN, así como documentación del Conservador de Bienes Raíces de Panguipulli y el Archivo de la Corporación Raíces de Toledo, recolección de documentos del COFOMAP por parte de personas naturales, pero que es dispersa e incompleta. También hemos recurrido a documentos digitalizados del Diario Oficial y del Congreso Nacional.

También contamos con testimonios de antiguos habitantes de Puñir-Releco, seis hombres y cinco mujeres que nacieron o habitaron en los predios que ocupan este estudio, por tanto, mayores de sesenta años y hoy residentes en diversos lugares de la región. Es importante comentar que los vecinos accedieron vía consentimiento informado a entregar sus recuerdos, y fueron consultados en la modalidad de entrevista semi estructurada, es decir, a partir de un cuestionario, se fue abriendo la conversación que llevó a evaluar e indagar en las categorías de esta investigación. Todos los testimonios fueron trabajadores del predio o familia de algún trabajador.

Por último, accedimos a fotografías recolectadas por la Corporación Entre Lagos y Montañas, que agrupa a los antiguos vecinos del fundo y que refleja fielmente el relato que aquí presentamos. Estas imágenes ayudan a evidenciar los testimonios graficando los elementos del relato.

\section{La etapa fundacional, el paternalismo desarmado}

Entraremos en la primera etapa de la explotación del fundo, aludiendo a un periodo en el que el paternalismo industrial clásico se encontraba en retirada en el país. Aun así, sus rasgos aún pueden ser evidenciados en predios como Puñir-Releco, reconocidos en las prácticas paternalistas que mencionamos. En ese sentido Hernán Venegas plantea la crisis del paternalismo, entre otras razones, porque "debió competir frente a las limitaciones impuestas por una presencia estatal cada vez más dinámica y omnipresente en las propias prácticas asistenciales clásicas del período" ${ }^{30}$.

La unidad productiva -conocida popularmente como fundo Puñir-Releco- fue propiedad de la Sociedad Echavarri Bravo limitada desde 1937 que, por una modificación en la sociedad, pasó

\footnotetext{
29 Illanes, María. 2003. Chile descentrado. Formación socio-cultural republicana y transición capitalista (1810-1910), Santiago, LOM, pp. 7-8

${ }^{30}$ Venegas, Hernán. 2014. "Paternalismo industrial y control social. Las experiencias disciplinadoras en la minería del carbón en Chile, Lota y Coronel en la primera mitad del siglo XX", en Les cahiers ALHIM, Vol. 28, disponible en https://journals.openedition.org/alhim/5099?lang=en
} 
a constituirse como Sociedad Releco agrícola y maderera limitada en 1947, con participación de la familia Bravo y otros ${ }^{31}$, a favor de la cual adquirieron los Fundos Releco y Puñir o Hacienda Puñire, como se le denominaba en aquel entonces. En 1954 esta sociedad fue disuelta y adjudicada, pasando a manos de Jorge Kuppenheim pero con participación de los hermanos Bravo en la nueva propiedad ${ }^{32}$. De esta manera, La hacienda Puñir-Releco tuvo en estas familias la cabeza y dirección en la etapa de explotación privada clásica, marcada por las prácticas paternalistas que conoceremos a continuación.

Para comenzar, es importante señalar que existió un aspecto de carácter paternalista de clásica formalidad, en el área de Releco, donde se vivió el encierro de la población trabajadora, en una forma de enclave que perpetuaba el control del tiempo y el cuerpo de las familias dedicadas a la actividad productiva. Puñir, por otra parte, estaba marcado por la conectividad que aportaba a la propiedad, el estar ubicado en la ribera del lago Panguipulli, agrupando un número importante, aunque voluble de familias. En la figura 1 el último vestigio del límite del predio Releco:

Figura 1. Entrada al predio Releco del fundo Puñir-Releco, 2018.

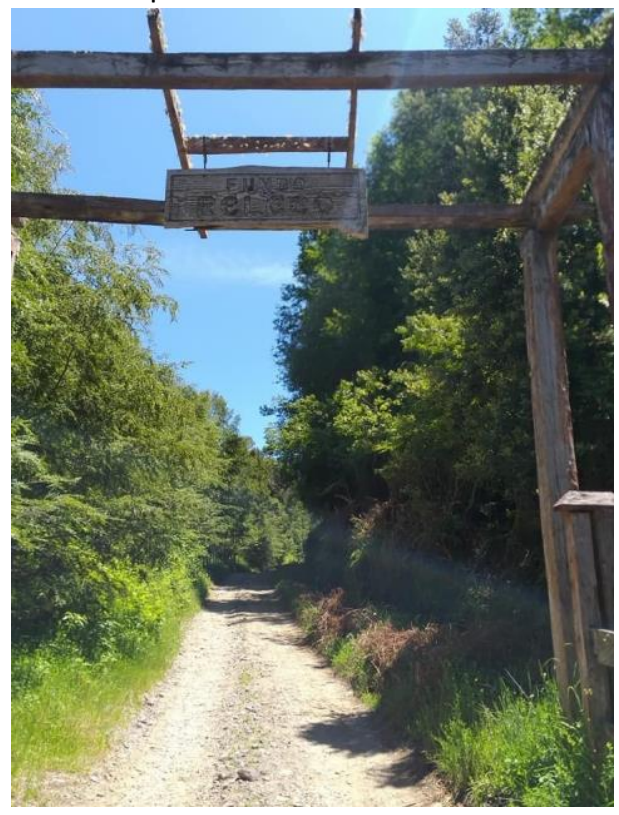

Fuente: Archivo Corporación Entre Lagos y Montañas

Ahora bien, se debe comprender que la existencia de una comunidad dentro de los predios de Puñir-Relecoe iba más allá de las relaciones sociales de producción que se podrían generar

\footnotetext{
${ }^{31}$ Conservador de Bienes Raíces de Valdivia. Inscripción N 134 Registro de Propiedad. 30 de diciembre de 1947.

${ }^{32}$ Conservador de Bienes Raíces de Valdivia. Inscripción N¹338 Registro de Propiedad. 4 de junio de 1954.
} 
en un ambiente laboral. Debemos señalar que la actividad que marcaba el ritmo fue el aserradero existente en Releco, allí se producía la riqueza del fundo y es allí donde llegaba todo el trabajo de los obreros que se internaban en los bosques de raulíes para extraer la materia prima y el consecuente trabajo industrial.

En relación con la edad de los varones para ingresar al trabajo forestal, como señalan los relatos, en general era a los 15 años. Es evidente que se abandonaban los estudios o, más bien no se proseguían, por razones de necesidad familiar para obtener mayores recursos, como se señala aquí: "mi hermano no alcanzó a terminar de estudiar, mi papá lo llevó a trabajar, porque como éramos siete, nueve con mis dos papás, no alcanzaba la mercadería para todos los meses. Mi papá tuvo que llevar a trabajar a mi hermano que era menor de edad para que le den medio quintal de harina más"33.

Por otra parte, los trabajadores que no realizaban tareas en el aserradero, o al interior de la montaña, se desempeñaron en diversas funciones administrativas, por ejemplo, en el manejo de bodegas o en el control de inventarios, atención de la pulpería, manejo de radio transmisores y otras tareas similares. Así, el tipo de especialización del trabajo dependía de la administración del predio forestal, incluidas actividades agrícolas y ganaderas demandadas por la empresa, cuestión que se mantuvo con la gestión del COFOMAP.

En este sentido, el sindicato fue el aspecto más relacionado a la acción de los trabajadores industriales de la época, dentro de la configuración de las propiedades del COFOMAP. Esto tuvo graves problemas, pues los diversos patrones no consideraron a sus trabajadores como industriales, insistiendo en su carácter de obreros agrícolas. Ahora bien, antes de la expropiación de los fundos forestales, cada uno de los predios que analizamos contaron con una agrupación sindical, según los testimonios recabados existieron proto sindicatos, pero fuera del conocimiento de los propietarios. Es el caso de Releco, donde debían reunirse clandestinamente, por miedo a represalias de los empleadores: "si, sindicatos, si estuve, bueno, en esos años se balanceaban ahí no más, les tiraba algo de plata el empleado al cabecilla y quedaban hasta ahí los acuerdos". ${ }^{34}$

En función de esa actividad y desde en un periodo temprano, existió una fuerte actividad relacionada con el transporte, que conectaba a los fundos desde Puñir para dirigirse a la ciudad más cercana, Panguipulli. La forma de transporte era la navegación lacustre, mediante el constante trayecto de los vapores Santa María y Bascuñán, embarcaciones que zarpaban desde el muelle de Puñir, con productos derivados del fundo para retornar con diversos aprovisionamientos para la pulpería, otro elemento específico del régimen paternalista que subsistió incluso en el periodo del COFOMAP.

\footnotetext{
33 Ester Retamal, comunicación personal, 22 de junio de 2019, Melefquén.

${ }^{34}$ Eduardo Sepúlveda, Comunicación personal, 16 de agosto de 2019, Neltume.
} 
Respecto al abastecimiento, tanto en lo relativo a la alimentación y otros productos, como en la vestimenta y artículos para el hogar, se realizaban mediante el sistema de pulpería. Allí se satisfacía el consumo de las familias de los trabajadores, generando una dependencia constante del sistema de consumo centralizado, es decir, la pulpería de propiedad del fundo, tal como señala un testimonio: "En la casa de pulpería que se nombraba, ahí había de todo, estaba de la papa pa' arriba hasta trigo había, tenían de todo, pero uno hacía esa lista y ellos completaban ... e iban repartiendo casa por casa" ${ }^{35}$. Pero el sistema generaba un sentimiento de gran inequidad y desazón en la población, pues, dañaba severamente la economía familiar:

"Había una pulpería una casa grande donde la gente llevaba sus listas, todos los meses era, claro, ya todos los meses llevaba su lista de lo que bastaba pal' mes y ahí, en la pulpería les sacaban cuenta cuánto gastaba en la pulpería y todo eso lo que gastaba le salía el sueldo al marido el tope, a veces le faltaba, así es que no le daban ni un peso al marido en el trabajo, no pagaban los trabajos, o sea, lo pagaban en pulpería, por eso mi hermano trabajó desde cabrito chico" ${ }^{36}$.

La pulpería es un dispositivo de control social y biopolítico que conocemos en otros sectores económicos y en otros territorios del país, pero que encontramos con gran fuerza y actividad en la zona. Esto indica que el régimen de prácticas paternalistas estaba siendo instalado y desarrollado por parte de propietarios que, hacia medianías del siglo XX, lo conocían y consideraban como la manera de establecer relaciones sociales de producción bajo su dominio. Sin duda la actividad industrial del primer tipo en la historia de la zona bebió de la experiencia histórica del capitalismo chileno marcado por ese paternalismo original, pues, los métodos y formas se asemejan bastante en este sentido.

Por otra parte, es interesante constatar que el establecimiento contaba con una cancha de fútbol y dos canchas de tenis, la más importante en la casa de huéspedes: "en la casa de huéspedes, donde iban todos los patrones, iban a pasear allá, a veranear a veces y se quedaban en esa casa de huéspedes, esa era una casa grande" ${ }^{37}$. Dentro del programa paternalista, la diferenciación de clases está muy definida y una forma de hacer ese marcaje de las relaciones sociales, en su carácter de habitar, es a través de espacios a los que solo acceden los patrones y su grupo, como es el caso de las canchas de tenis, en cambio, el fútbol era la práctica habitual para los trabajadores.

Según declaran los testimonios, el edificio de la escuela de Puñir albergó a diversidad de cursos y contó con una matrícula que variaba entre 40 y 50 estudiantes, todos pertenecientes

\footnotetext{
35 Ema Arias, comunicación personal, 22 de junio de 2019, Melefquén.

${ }^{36}$ Ester Retamal, comunicación personal, 22 de junio de 2019, Melefquén.

37 Ester Retamal, comunicación personal, 22 de junio de 2019, Melefquén.
} 
a las familias que vivían y trabajaban en los dos fundos de la propiedad de los Bravo. Pero una cuestión relevante que demarca el tipo de práctica paternalista en este sentido está dada por la dependencia del establecimiento. Fue al Estado quien se hizo cargo de la gestión escolar. La empresa aportó con su construcción y con la habilitación de espacios para la vivienda de las y los docentes. La escuela fue vital en las diferentes actividades y organizaciones de la comunidad de trabajadores forestales: "Releco tenía una población que estaba alrededor, eran dos calles que estaban eh, un conjunto habitacional, debe haber tenido unas treinta casas en esa parte, estaba el colegio al centro, que cumplía la función de colegio y de iglesia y centro de reuniones, todo, eso lo había construido la empresa" ${ }^{38}$.

Uno de los aspectos significativos de los asentamientos es la presencia de escuelas. En el área de Puñir, existió una escuela que tuvo actividad con una profesora, contratada por la familia Bravo, que aumentó su capacidad cuando la actividad maderera comenzó a desarrollarse con mayor fuerza: "si había hartos [niños] y después ya se hizo una escuela grande, cuando ya empezó el movimiento de madera allá se hicieron, una escuela grande" ${ }^{39}$. En Releco la actividad pedagógica funcionó en la relación con instituciones externas, como es el caso de la Iglesia católica.

Particularmente en Releco, el establecimiento escolar fue administrado por el Magisterio de la Araucanía ${ }^{40}$, dando orientación católica a la enseñanza, cuestión que fue bastante habitual en la época y en estos territorios de montaña, pues, este magisterio tuvo a su cargo escuelas por toda la cordillera valdiviana. La escuela era de tipo multigrado y en base a los relatos de los antiguos habitantes, fueron dos profesoras las que desarrollaron el trabajo pedagógico en Releco, siempre bajo la supervisión de la institución católica con sede en la ciudad de Villarrica.

Por otra parte, el establecimiento escolar de Puñir fue de propiedad fiscal, aunque cedido a la Corporación municipal de Panguipulli en sus últimos años. Aquí también se produce una situación similar, en tanto el edificio de la escuela era propiedad del fundo; algunos testimonios relatan los problemas que esto significó, por ejemplo, cuando se necesitaba reparaciones en el edificio, como indica un ex profesor del colegio:

"ellos (la corporación municipal) no podían invertir en terrenos particulares, porque a mí me costó un mundo pa' que me pudieran dar zinc cuando techamos la parte norte de la escuela... era fiscal, estaba cedida a la corporación en este caso y antes era cedida al

\footnotetext{
38 Alen Vidal, comunicación personal, 16 de agosto de 2019, Melefquén.

${ }^{39}$ Eduardo Sepúlveda, comunicación personal, 16 de agosto de 2019, Neltume.

${ }^{40}$ Alarcón, Natalia. 2018. "Usted entenderá en milímetros, yo entiendo en pulgadas": Educación rural en los fundos del territorio cordillerano de la provincia de Valdivia durante el periodo de la Reforma y Contra Reforma Agraria. (1960-1990). Universidad Austral de Chile. Tesis para optar al grado de Profesora de Historia y Ciencias Sociales, pp. $42-48$.
} 
Ministerio de Educación, por lo tanto, la escuela era un edificio del fundo, mientras yo estuve ahí teníamos problemas, por ejemplo, para hacer reparaciones porque recursos del Estado no podían arreglar, o sea, no pueden arreglar algo que es particular y en ese caso la escuela estaba en comodato por la corporación" ${ }^{41}$.

Este tipo de acontecimientos nos revela la estrecha relación que existió entre los propietarios del fundo y los servicios educativos públicos, destinados al desarrollo social y político de los habitantes, toda vez que se consideraba una población abandonada por la acción del Estado y que era necesario incorporar al proyecto nacional ${ }^{42}$.

Una cuestión de gran interés guarda relación con el emplazamiento de la escuela de Puñir. Esta se situó en un espacio que podemos considerar parte de un pueblo o área comunitaria, incluyéndola en un circuito que agregaba diferentes servicios de enorme importancia para la población, incluyendo la agrupación de viviendas que generaban un programa fundamental: la función habitacional que permitía la producción de la vida, en particular de la vida moderna a la que eran convocados en tanto trabajadores que aportaban al desarrollo nacional; durante décadas, casa, aserradero y escuela nos indica la conformación de una comunidad que estructura formas de habitar signadas por la acción afirmativa de la empresa y su régimen. La instalación, como se observa en la imagen 2, tuvo un colectivo de viviendas para solteros, elemento propio de los regímenes paternalistas que, hacia los ochenta, desapareció.

Otras modalidades heredadas del programa paternalista en los fundos Puñir y Releco guardan relación con el acceso a diversos elementos de la modernización desarrollista que, por una parte, aleja a la población de la concepción tradicional de ruralidad y, por otro lado, los conecta con el discurso que les promete el progreso y la integración. Entre estos elementos significantes podemos considerar la electricidad, como veremos en seguida.

La llegada del muy moderno servicio de electricidad hizo posible la adquisición y utilización de electrodomésticos al interior de las viviendas (Figura 3), lo que fue generando transformaciones importantes en el estilo de vida, que podríamos calificar como más cercano a lo urbano. En tanto urbano se acerca a moderno, los habitantes de Puñir y Releco fueron desarrollando, gracias a estas incorporaciones, una forma de habitar propia de los trabajadores conectados a la modernidad, pero siempre de una forma periférica, tal vez por eso es de destacar que el enclave forestal no se puede asociar inmediatamente a la imagen que se elaboró del campesinado sureño en la segunda mitad del siglo XX.

\footnotetext{
${ }^{41}$ Martín Contreras, comunicación personal, 9 de agosto de 2019 Panguipulli.

${ }^{42}$ Salazar, Gabriel. 2003. Historia de la acumulación capitalista en Chile: Apuntes de clase. Santiago, LOM. Sunkel, Osvaldo. 2011. El presente como historia. Dos siglos de cambio y frustración en Chile, Santiago, Catalonia. Ambos autores demuestran el tenor del proyecto nacional desarrollista, preocupado de generar ciudadanía al consolidar relaciones sociales con el Estado como constructor de un proyecto modernizador.
} 
Figura 2. Pulpería de Releco entre 1950 y 1960.

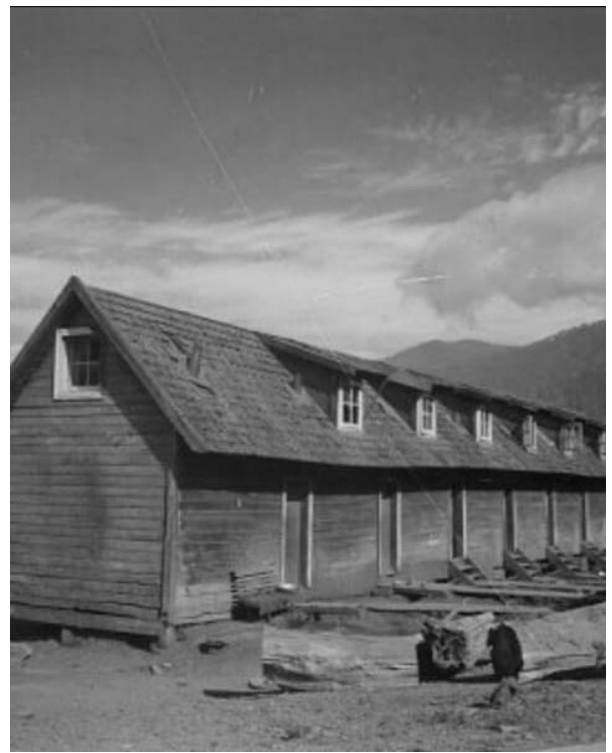

Fuente: Archivo Fotográfico Andrés Bello Universidad de Chile

Figura 3. Familia Palma Sepúlveda en Releco, circa 1971.

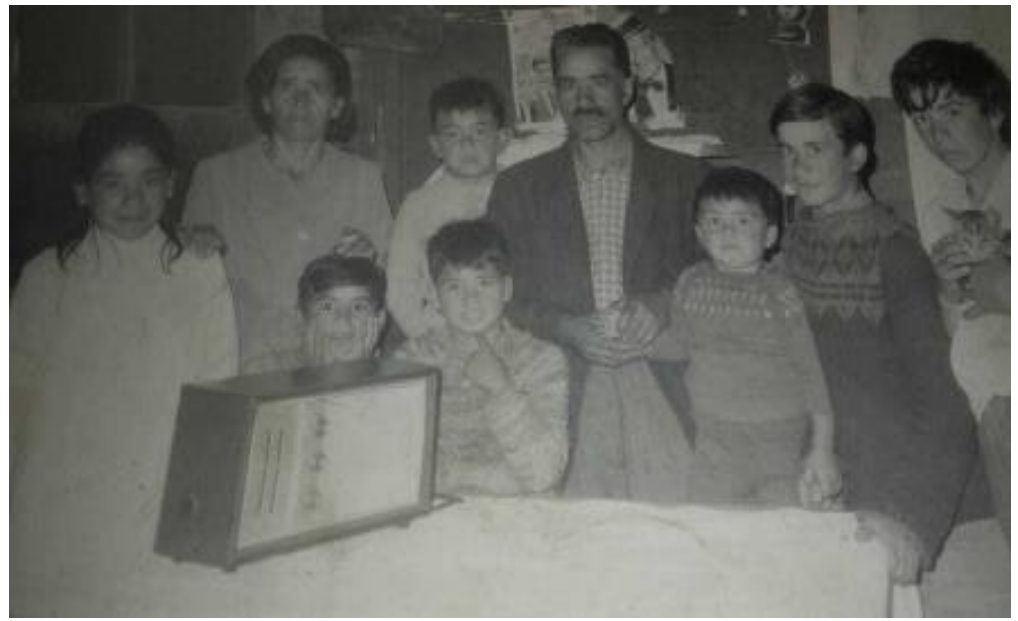

Fuente: Archivo Corporación Entre Lagos y Montañas.

Por otra parte, resulta interesante dar a conocer la presencia de una brigada de bomberos en Puñir, que, como indican los testimonios, no estuvo bien organizada desde su inicio. Con el paso de los años, la compañía fue allegando recursos. La imagen de los bomberos de Puñir (figura 4), exhibe a los voluntarios con sus uniformes, carro y mangueras, además de su participación en los desfiles de la comunidad, otra forma de modernización y guiño al Estado y 
su discurso. Una de los informantes indica: "también fui bombero, sí, como había pocos, había que, ahí mismo en Puñir en el centro que llamábamos, al ladito de una bodega grande" ${ }^{43}$. Por otra parte, en Releco no existió esta institución, aunque la relación de los habitantes de Releco con los bomberos de Puñir daba sentido de pertenencia a la comunidad, adosándoles un valor de pertenencia ciudadana al Estado moderno, más valioso en el contexto de la lejanía de esa zona, tal como se manifiesta en la imagen (figura 4).

Figura 4. Bomberos de Puñir en desfile por el 18 de septiembre, 1971.

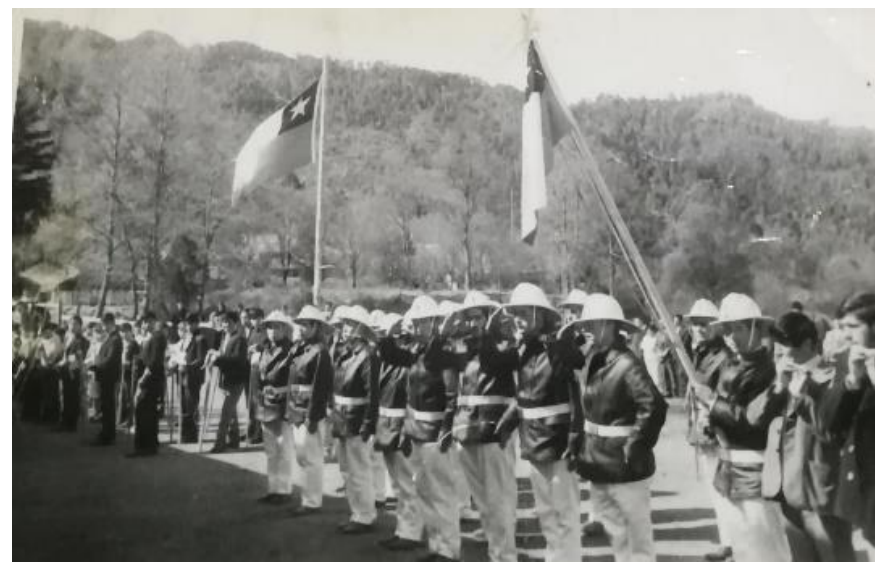

Fuente: Archivo Corporación Entre Lagos y Montañas.

Figura 5. Escuela de Releco, 1974.

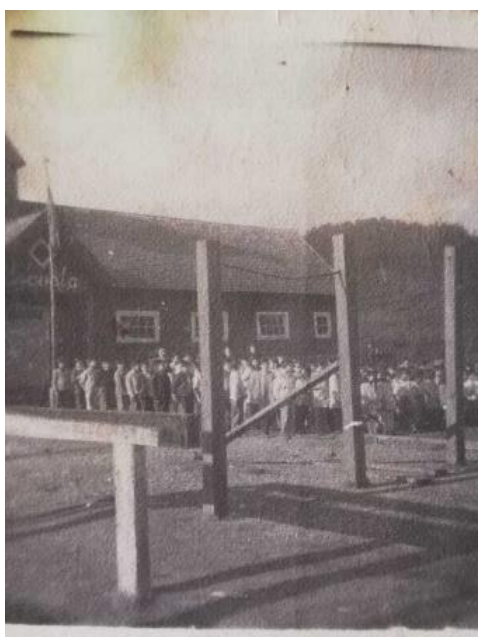

Fuente: Archivo Corporación Entre Lagos y Montañas

43 J. B., comunicación personal, 9 de agosto de 2019, Panguipulli. 
Como se observa en la figura 5, la institución escolar fue parte de la vida social del predio, incluidas las ceremonias que definen la presencia del Estado en el "izamiento de la bandera", como se ve en la fotografía.

Es relevante señalar que en Releco, dada la presencia de la escuela católica y el magisterio de la Araucanía a través suyo, hacía que un sacerdote viajara habitualmente hasta el enclave forestal: "el cura iba a hacer misas a la escuela, iba desde Pangui, ahí nos bautizamos casi todos nosotros", 44 entregando los sacramentos a los fieles del pueblo y realizando fiestas como bautizos y otras ceremonias en el mismo recinto de la escuela. Respecto a otros temas religiosos, podemos indicar que en Puñir existieron cultos evangélicos que se realizaron privadamente al interior de casas particulares; no se manifestó un templo para estas actividades en ninguno de los dos poblados.

Figura 6. Club Deportivo Juventud Releco, circa 1970.

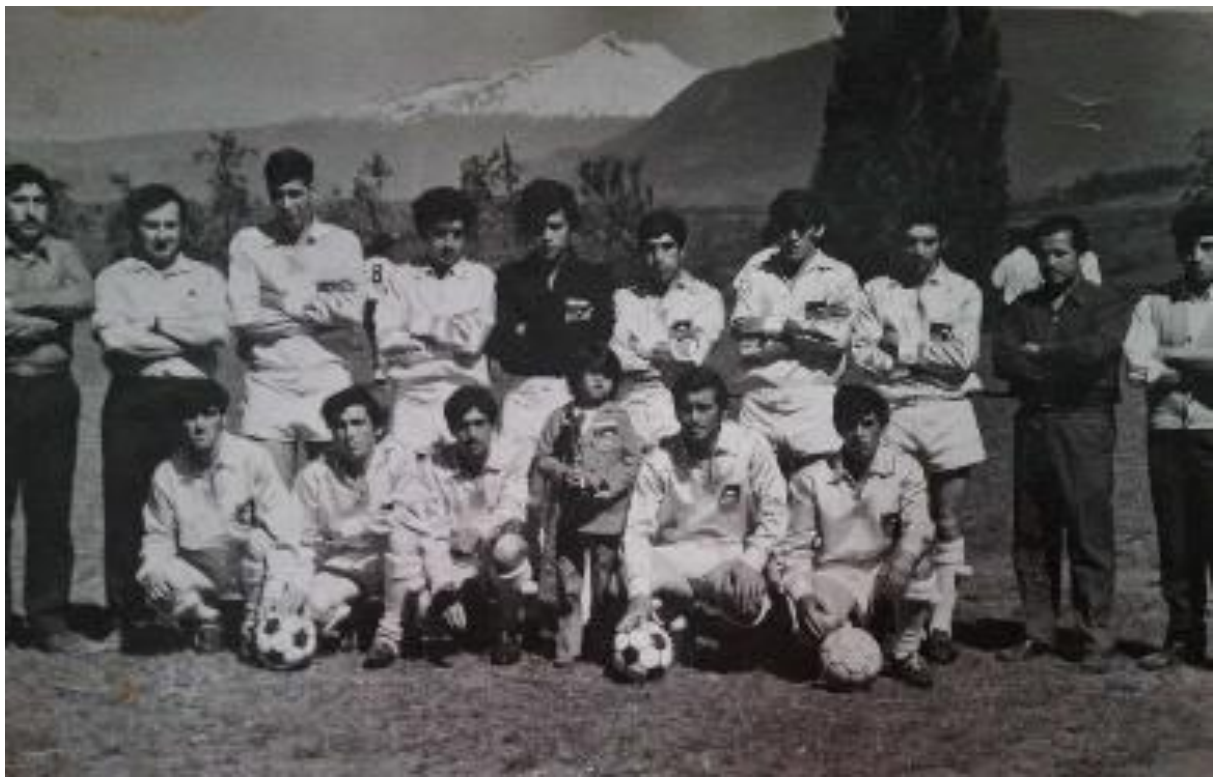

Fuente: Archivo Corporación Entre Lagos y Montañas

Desde buen inicio de la actividad forestal en la zona, las prácticas deportivas fueron significativas y no solo por la cuestión relativa al control social de los cuerpos trabajadores, también fue importante por la acción recreativa que lograba la reunión de las familias, cuestión que desde la mirada de los trabajadores tuvo un gran valor. Los campeonatos de fútbol fueron los eventos que lograban este activo espacio lúdico, tanto Releco como Puñir contaban con sus respectivos equipos. Ellos conformaron una liga que generó encuentros con otros equipos de

44 Ema Arias, comunicación personal, 22 de junio de 2019, Melefquén. 
fundos madereros de la zona, la mayoría de los jugadores fueron trabajadores de los mismos predios forestales y se integraron a la actividad mediante distintas categorías etarias que practicaban el fútbol cada semana.

"Teníamos un club deportivo, pucha, como treinta personas jugando, ahí nos juntábamos todas las tardes a deportear (sic), los días domingo igual y todo en la cancha, no teníamos sede y de ahí, después, nos regalaron una casita bien chica y nosotros la hicimos sede, ahí colocábamos los trofeos que nos ganábamos, pero era chiquitita, no cabíamos todos adentro... pucha como del 81 [año] más o menos" ${ }^{\prime 4}$.

También, y dentro de las actividades de diversión y recreo, las celebraciones como las del 18 de septiembre son claramente recordadas por los antiguos habitantes. En Puñir se realizaban las típicas ramadas chilenas en la cancha de fútbol del fundo. Por otro lado, la cultura campesina estaba presente en el cotidiano de las personas, como recuerda un testimonio: "Igual se celebraba el San Juan, eso era, san Juan, las Cármenes me acuerdo de cuando era cabra chica yo" 46 .

Pero además de esta fiesta, también se efectuaron eventos como bailes o bingos, con el fin de reunir dineros para, por ejemplo, pintar la escuela: "yo del beneficio que más me acuerdo, porque fue ostentoso, fue grande, un año que hicimos hacer regalos pa' los niños, pa' navidad" ${ }^{47}$. Los testimonios expresan que todos y todas se reunían periódicamente para celebrar -como comunidad- las diferentes festividades propias de un pueblo pequeño. En este sentido, las actividades nos hablan de la cohesión y vida activa de estas comunidades, dando cuenta del aspecto civil y ciudadano que primaba en sus relaciones.

Las relaciones sociales, revisadas a la luz de los testimonios, definen que las prácticas paternalistas fueron mediatizadas por la constitución de iniciativas propias de las y los habitantes-trabajadores del predio, sus necesidades fueron siendo identificadas no desde la gestión del empresario y su acción consecutiva. Aunque no del todo, vemos como en muchas ocasiones se da por actividades propias de los obreros y sus familias, las relaciones entre ellos y el patrón; entonces, se desarma en la creciente acción autogestionada de la comunidad.

De esta forma, y una vez revisada la evidencia, el régimen de prácticas paternalistas, llegados los años setenta, estaba en pleno desarme o en decadencia. Todo esto tuvo una detención radical con los sucesos que se desarrollaron con la toma de los fundos Puñir y Releco y su posterior incorporación al proyecto de control obrero de las faenas, cuestión que revisaremos a continuación.

\footnotetext{
45 J. B., comunicación personal, 9 de agosto de 2019, Panguipulli.

${ }^{46}$ Ester Retamal, comunicación personal, 22 de junio de 2019, Melefquén.

${ }^{47}$ Martín Contreras, comunicación personal, 9 de agosto de 2019 Panguipulli.
} 


\section{Era de transformaciones: el COFOMAP}

En este apartado trataremos el proceso histórico que, iniciado con la Reforma Agraria, fue constituyendo una movilización sin parangón en los campos chilenos. Si bien los trabajadores forestales de la zona no pueden calificarse como campesinos, la zona precordillerana se levantó en múltiples tomas de predios forestales, dando paso a la constitución de una empresa estatal que tuvo una inusual forma de administración, que hizo a los trabajadores los sujetos centrales en la administración -antes privada- de los fundos. Aquí veremos el origen de la empresa y su devenir en los predios de Releco y Puñir.

Definimos como trabajadores forestales a la población del área, por el tipo de faenas que realizan, cercanas a la industria más que al agro. Por otra parte, el tipo de actividades que constatamos a través de las fotografías nos llevan a relatar el proceso de proletarización y modernización del que hemos hablado anteriormente.

Recién iniciados los años setenta y en medio de los nuevos vientos que trajo la elección de Salvador Allende, cientos de fundos en todo el país fueron tomados. La provincia de Valdivia se implicó fuertemente en ese proceso, siendo de las más movilizadas en pos de la transformación en el régimen de propiedad ${ }^{48}$. Releco y Puñir no quedaron exentos de este proceso y los relatos acerca de este proceso se suceden entre los antiguos habitantes.

Fue el día 20 de enero de 1971 cuando se produjo la toma del predio Releco, uno de los que nos convoca. "40 obreros del fundo de la firma maderera Releco, procedieron a la ocupación de éste, exigiendo aumento de sueldos" ${ }^{49}$. Si bien la demanda apuntada por el senado de la República tocaba la cuestión de las mejoras salariales, cabe destacar que la ocupación buscaba una transformación radical en las relaciones sociales existentes entre patrón y trabajadores. Al día siguiente, 137 obreros forestales que trabajaban para el fundo Puñir ocuparon este predio, ${ }^{50}$ siguiendo la acción de sus compañeros de Releco, es decir, la movilización representó la decisión consensuada del colectivo de trabajadores del fundo, ${ }^{51}$ hasta ese momento, propiedad de la familia Bravo.

Las ocupaciones de ambos predios fueron acciones esperadas en el marco del levantamiento general de los trabajadores en toda la zona forestal de la provincia valdiviana. Por todos los fundos se repitieron estas movilizaciones por parte de los obreros. En Releco y en Puñir no se registraron incidentes violentos, primando la alegría de los ocupantes y, a partir de

\footnotetext{
48 Morales. 2020. Pan, tierra y socialismo, pp. 59-61.

49 Diario de sesiones del Senado (1972) Legislatura 316 ordinaria, p. 311

${ }^{50}$ Diario de sesiones del Senado (1972) Legislatura 316 ordinaria, p.313

${ }^{51}$ Es importante apuntar el rol del MIR en esta decisión del grupo de trabajadores, tal como apunta Palieraki, E. iLa revolución ya viene!, p. 280 quien atestigua con documentos la participación y promesa de ayuda de militantes del MIR para llevar a cabo la toma de Puñir.
} 
las tomas, se ejecutaron los traspasos de propiedad desde los patrones a la Corporación de Reforma Agraria sin mayores inconvenientes.

"cuando ya salió el presidente Allende entonces vinieron de Santiago, vino una fuerza militar a Puñir a tomar el fundo, a intervenirlo, porque Puñir fue intervenido, no fue tomado por la gente, vinieron de allá, estuvimos parados nosotros, nos pararon ahí como dos horas, hicieron una reunión con toda la gente los militares, pusieron antenas en un rato ahí, llamaban pa' cualquier lado y como dos horas estuvieron parados y de repente ya, ahora cada cual se va a sus puestos no más, a trabajar, el fundo está intervenido" 52 .

Los trabajadores, recordando la historia de sus padres y abuelos, sentían que había llegado el tiempo para hacerse de un espacio de gestión propio que -incluyendo el trabajo-, les permitiera acceder a la soberanía para reproducir la vida en aquellos lugares: "Ios tres años del complejo maderero fue una zona, para nosotros, del complejo maderero flamante, tuvimos lo que nunca habíamos tenido, por ejemplo, dinero y derechos laborales" ${ }^{53}$. En efecto, después de las tomas de los fundos, el trabajo y las formas de vida en la zona se transformaron profundamente. Fue una nueva manera de establecer las relaciones sociales de producción, aunque no sin dificultades.

En nuestro caso, y una vez instaladas las tomas en la propiedad de la familia Bravo, la Corporación de la Reforma Agraria (CORA) procedió a la expropiación del fundo, hecho que se concretó el día 12 de marzo de 1971 por acuerdo de esa entidad, la número 306. La enajenación de Puñir-Releco se realizó aludiendo a la mala explotación de la propiedad, como se definió en la mayor parte de las expropiaciones; ${ }^{54}$ junto a este proceso legal comenzó una nueva etapa para estos predios, marcada por la incorporación a la nueva empresa estatal creada para desarrollar las explotaciones de la zona desde un ente público, Puñir y Releco entraron al Complejo Forestal y Maderero de Panguipulli, cuestión que se produjo casi inmediatamente, pues el COFOMAP vio la luz, legalmente, el 7 de octubre de $1971^{55}$.

Es importante hacer una diferenciación respecto a ambas propiedades que, si bien siempre se entendieron juntas, tuvieron una especialización que continuó existiendo en la etapa estatal del fundo. De esta manera podemos establecer que la diferencia fundamental tiene que ver con la actividad productiva de ambos predios. Por una parte, Releco tuvo una clara vocación

\footnotetext{
52 Eduardo Sepúlveda, Comunicación personal, 16 de agosto de 2019, Neltume.

53 Juan Vásquez, comunicación personal, 16 de agosto de 2019, Panguipulli.

${ }^{54}$ Diario Oficial de la República de Chile, 15 de marzo de 1971, p. 1014.

55 Diario Oficial de la República de Chile, 15 de octubre de 1971, p. 4141. La inscripción fue hecha en la notaría de Herman Chadwick Valdés, de Santiago, el 7 de octubre de 1971.
} 
maderera, mientras que Puñir se orientó hacia la explotación agrícola-ganadera de la propiedad, aunque también explotó un aserradero menor.

Por otra parte, es relevante señalar el gran valor del fundo Puñir-Releco en términos del aporte económico que hizo a la estatal COFOMAP, cuestión que le valió ser considerado como una de las propiedades fuertes de la empresa. Según algunas cifras disponibles, el fundo concentraba a 270 trabajadores en $1972^{56}$. Si bien los números se dan para trabajadores contratados en ambos predios, a ello hay que sumar los obreros de temporada, los no contratados directamente por la estatal y al no despreciable número de habitantes que aportaban las familias de los obreros forestales; con ello podemos considerar una población cercana al millar de personas en Puñir-Releco. De esta manera, podemos observar que la dimensión del fundo, en el total del COFOMAP, era significativa.

Un elemento que debemos constatar de manera relevante fue el trabajo desarrollado por las mujeres, que se ocuparon de las importantes tareas de la reproducción de la vida, consistente en las siempre despreciadas tareas del hogar. En este punto debemos detenernos en el cultivo y sostenimiento de pequeñas huertas y crianza de animales: "porque ahí todos criaban po', nuestros papás criaban sus animales así es que era bueno, ahora hay que andar comprando un pedacito de carne para comérselo antes no pues, ahí carneaban sus chanchos" ${ }^{27}$.

Toda esa actividad, permitida por el COFOMAP sin problemas, como lo había sido también en el régimen anterior, significó el desarrollo de economías locales que complementaron el abastecimiento de la pulpería, afirmando la idea de prácticas paternalistas lejanas al modelo clásico, pero en convivencia con el nuevo régimen de relaciones sociales de corte socialista y colaborativo que se intentaba construir.

También es importante señalar que, en algunas oportunidades, hubo mujeres que se dedicaron a diversas actividades, en el marco de las carencias propias marcadas por el machismo también presente en el territorio: "en mi casa nunca me dejaron trabajar, después me casé, tampoco trabajaba, después que me separé tuve que aprender a trabajar en lo que era fruta, toda la cuestión", ${ }^{58}$ o en algunas tradicionales formas del trabajo de los sectores populares vinculados a los regímenes del trabajo temporal, como ocurría en los años en que se instaló el COFOMAP; "[mi mamá era] dueña de casa y daba pensión, si tenía pensión, daba pensión, a los trabajadores de ahí mismo del fundo" ${ }^{59}$. Efectivamente, estas labores, casa y

\footnotetext{
${ }^{56}$ Galilea, Sergio et.al. 1972. "Agentes políticos y reestructuración del espacio y la producción en una región de Chile" en Revista EURE, Santiago, 2 (4), p. 72.

57 Sonia Hernández, comunicación personal, 14 de agosto de 2019, Melefquén.

58 Irma Álvarez, comunicación personal, 10 de agosto de 2019, Melefquen.

59 Sonia Hernández, comunicación personal, 14 de agosto de 2019, Melefquén.
} 
comida para trabajadores temporales fueron generando nuevos y distintos ingresos al núcleo familiar gracias al trabajo femenino.

Ahora bien, con el desarrollo del COFOMAP van a aparecer, lentamente, algunos nuevos empleos en que las mujeres comenzaron a hacerse parte, en cuanto el COFOMAP desarrolló proyectos apícolas, manufacturas o en la administración. Poco a poco, las mujeres fueron haciéndose espacio en el mundo laboral de la montaña. Estos proyectos comenzaron a implementarse, y aunque fueron pocas mujeres las que se emplearon por estas vías, no rompían con las relaciones tradicionales asignadas al género.

"Perfeccionar y proporcionar a la dueña de casa los conocimientos necesarios para la confección de ropa más compleja de la familia y adornos utilizados en ella, como asimismo enseñar las técnicas de nutrición, manipulación y conservación de alimentos.

Para la realización de estos proyectos INACAP requiere de una dotación adecuada de equipos cuyo costo asciende a US\$26.000 y de un total de US\$ 37.856 para otorgar becas a las jóvenes que por sus condiciones socioeconómicas lo requieren para el término de sus cursos" ${ }^{\prime 60}$.

Una cuestión de gran significación para el fundo durante esta etapa, y para el conjunto de los predios incluidos en el COFOMAP, fue el engrandecimiento de la compleja red de caminos que, desde antiguo fueron construidos por los trabajadores de la zona. Ello les permitió comunicarse entre los diversos poblados $y$, a través de estas labores, el COFOMAP fue mejorando la gestión del territorio en lo económico y lo social. En lo que respecta a Puñir y Releco, hacia la década del setenta, comenzó la habilitación de un camino que bordea el lago Panguipulli y que conecta la cabecera municipal desde Panguipulli hacia Choshuenco. Con ello se fue haciendo innecesaria la vía de movilización lacustre, haciendo mucho más asequible el traslado de los habitantes del fundo hacia la ciudad de Panguipulli y los servicios públicos y privados alojados allí. Esto obedeció a la política de desarrollo del COFOMAP y del gobierno respecto a fortalecer la infraestructura de la zona: “El programa de lo zona fronteriza, centra su preocupación de corto plazo en tres aspectos fundamentales: a) habilitación territorial, sobre la base de la ampliación de la red vial y el refuerzo en el equipamiento social básico..." ${ }^{61}$.

\footnotetext{
60 ODEPLAN. Programa de desarrollo social integrado para las provincias de Cautín, Valdivia y Osorno. Diciembre de 1972., pp. 43-44. Recuperado de: http://www.desarrollosocialyfamilia.gob.cl/btca/txtcompleto/DIGITALIZADOS/ODEPLAN/O32Ppd-1972.pdf Consultado el 2 de diciembre de 2020.

61 ODEPLAN. Resumen del plan anual 1972. Enero de 1972, p. 81. Recuperado de: http://www.desarrollosocialyfamilia.gob.cl/btca/txtcompleto/DIGITALIZADOS/ODEPLAN/O32Pr-1972.pdf Consultado 2 de diciembre de 2020
} 
Una de las cuestiones de importancia en la experiencia del COFOMAP, es la introducción del cuidado del medio ambiente, tal como lo señala el segundo de los objetivos que declara en su conformación: "2.- La conservación y preservación de los recursos naturales del área geográfica bajo su administración" ${ }^{62}$. Esta fue una de las transformaciones en el manejo de las explotaciones forestales, antes hechas según las definiciones de los patrones, ahora se incluyeron parámetros científicos y técnicos para su manejo, cuestión que perduró una vez instalada la dictadura, como lo señala el INFOR en 1977:

"Por ser el bosque nativo un recurso de incalculable valor tanto económico como de producción, el Complejo Forestal Panguipulli desarrolla en esta zona intensas actividades silvícolas tendientes a mantener el control del recurso que asegure su continuidad y calidad. De este modo, la explotación del bosque se efectúa en forma racional y equilibrada de acuerdo a planes de manejo ateniéndose a todas las disposiciones vigentes al respecto (Decreto Ley 701)"

Todas estas iniciativas reforzaron los saberes y necesidades de los trabajadores y familias de la montaña, impulsadas fuertemente por su presencia en el consejo de administración y el debate político que empujaba por transformaciones como las apuntadas aquí. Cuestiones relativas al género, la participación democrática de los obreros en la gestión y el manejo adecuado de las explotaciones marcaron, entre otras temáticas, el devenir de los cortos años de la Unidad Popular en estos fundos y poblados.

Por último, la importante movilización obrera que dio origen al COFOMAP y en el caso de Puñir y Releco, se desarrolló con una tranquilidad que cuesta entender a la luz de la fuerte represión desatada años después. Los testimonios son claros en señalar que el paso dado para recobrar dominio sobre el territorio fue producto de una fuerte convicción y parte del proceso político general que vivía el país a inicios de la década del setenta. El COFOMAP es visto aquí como una consecuencia de décadas de sufrido y no reconocido trabajo de los trabajadores y sus familias. Fue una salida concreta para mejorar las condiciones de vida en el fundo y según hemos conocido así se valoró.

El COFOMAP como proyecto estatal de cogestión obrera tuvo un quiebre brutal producto del golpe de Estado de 1973. Si bien la empresa no fue cerrada, esta vivió un complicado proceso de modificaciones que terminaron con su espíritu original. Ahora veremos cómo se fue dando ese proceso de destrucción de esa unidad económica en medio del desarrollo del proyecto neoliberal enarbolado por la dictadura.

\footnotetext{
62 ARNAD, Fondo CORFO, COFOMAP. Breve síntesis del Complejo forestal y maderero Panguipulli COFOMAP Ltda. 1974. Volumen 136, p. 2.

63 INFOR. Complejo Forestal y Maderero Panguipulli. 17 de enero de 1977, s/p.
} 


\section{Los años de la decadencia, dictadura en la montaña}

Una vez instalada la dictadura cívico-militar en el país, en todo el territorio de la cordillera valdiviana se produce una fuerte acción represiva. El denominado terrorismo de Estado fue sentido y sufrido por los vecinos de Puñir y Releco con especial temor. Un gran número de efectivos militares fueron recorriendo la zona de manera permanente tras el golpe de Estado, "rondando incluso por las noches muy cerca de las casas y trajinando casas de vecinos" ${ }^{64}$. El nivel de terror provocado por la persecución política generó un problema que terminó por derrumbar las relaciones sociales tal como fueron construidas en las décadas precedentes. Ello significó el final de la forma de vida, comunitaria y solidaria, de fundos como Puñir y Releco. La nueva autoridad definió el fin de esta forma de vida y trabajo en el territorio y lo definió en decisiones como estas:

"El personal que habita en casas y/o terrenos del COFOMAP, tomará nota de lo que sigue:

1.- Que a contar del 01.01.77, quedan prohibidas las chacras dentro del COMPLEJO. En este caso quedan autorizadas las cosechas de las ya autorizadas (sic).-

2.- Que solamente gozarán de esta regalía, aquellos trabajadores que no reciban luz eléctrica del COMPLEJO.-

En estos casos, las chacras, no excederán de $1 / 2$ hectárea y estarán inmediatamente contiguas a las casas habitación del trabajador.

3.- Que los trabajadores que viven dentro de los límites del COMPLEJO y que deseen trasladarse fuera de estos límites, la empresa les ofrece a título gratuito, por concepto de compensación, lo siguiente:
a.- La casa que ocupa
b.- 200 pulgadas de Ulmo V.
c.- $1.500,00$ en efectivo" ${ }^{\prime \prime}$.

Una primera consecuencia de esta forma de violencia estatal se manifestó en la expulsión de las familias de los fundos, toda vez que parezca un beneficio. La empresa a cargo de Ponce Lerou no negoció estas condiciones y los testimonios lo reflejan como un acto de violencia; muchas de estas personas fueron echadas de sus trabajos y de sus viviendas, otras tantas, por miedo a ser descubiertas o denunciadas decidieron marcharse por propia voluntad, aun así,

\footnotetext{
64 Tránsita Guarda, comunicación personal, 21 de junio de 2019, Melefquén.

65 Archivo Corporación Raíces de Toledo. "Memorando interno N 10", 10 de diciembre de 1976. Es decir, Julio Ponce Lerou dio 20 días a las familias para aceptar estas condiciones y abandonar las viviendas.
} 
hubo familias que permanecieron: "la gente se quedó ahí no más, no quiso salir, pero solamente con el mínimo, con lo que el gobierno les daba" ${ }^{66}$.

Por otra parte, y respecto al plano más directo del terrorismo de Estado, en el predio Releco se produjeron impactantes detenciones y otras formas de amedrentamiento hacia los habitantes del poblado, tal como señalan los vecinos en los días posteriores al 11 de septiembre de 1973:

"Ios que trabajan ahí en la huincha los fueron a agarrar a todos los milicos, los que escaparon fueron los que trabajaban en la montaña [...] algunos debieron salir de sus casas porque hace dos meses no venían a pagar los sueldos y ellos vieron unos vehículos que venían por la montaña de al frente, entonces creyeron que les venían a pagar, pero eran los milicos y ahí los pescaron" ${ }^{67}$.

Según continúan las memorias de los antiguos vecinos del fundo, las fuerzas militares hicieron permanentes recorridos por la propiedad forestal, fueron entrando a las distintas viviendas, allí realizaron detenciones en lugares públicos de la zona, también efectuaron detenciones ilegales y apremios ilegítimos: "después que los apalearon, los apalearon, los pisaron me acuerdo, les pisaban las cabezas, en la tierra, en la piedra, los pararon y después los pasaron por la calle de atrás" ${ }^{68}$. En los dos predios del fundo fue impuesto el toque de queda, lo que significó la prohibición tajante de circular a ciertas horas; "si, en Puñir, si, los jóvenes no podían salir, si salían los agarraban y los iban a dejar a la casa" ${ }^{69}$. Aun así, es importante señalar que los ex habitantes de Puñir y Releco señalan que no fueron tan golpeados durante esos días de pánico, como si lo fue el vecino pueblo de Neltume, de mayor cantidad de habitantes y con severos daños a los derechos humanos de su población ${ }^{70}$.

Pese a aquello y respecto a los delitos de lesa humanidad cometidos allí, el denominado informe Valech consigna que los hechos más significativos ocurrieron, tal como señalan los testimonios, en la casa de la administración del Fundo Releco, ${ }^{71}$ local que funcionó como centro de detención y torturas para quienes fueron detenidos y hechos prisioneros allí, es decir, los trabajadores de los predios del fundo. Esto nos señala que la vulneración de los derechos fundamentales no solo no fue ajeno a la localidad, si no que consideró el uso de espacios del

\footnotetext{
66 Ester Retamal, comunicación personal, 22 de junio de 2019, Melefquén.

${ }^{67}$ Ema Arias, comunicación personal, 22 de junio de 2019, Melefquén

68 Ester Retamal, comunicación personal, 22 de junio de 2019, Melefquén.

${ }^{69}$ Sonia Hernández, comunicación personal, 14 de agosto de 2019, Melefquén.

70 CODEPU. 1991. Chile, recuerdos de la guerra. pp. 43-55, tienen detalles de estos hechos en Neltume.

${ }^{71}$ Comisión nacional sobre prisión política y tortura. 2005. Informe de la Comisión nacional sobre prisión política y tortura. Santiago. Ministerio del Interior, p. 411.
} 
poblado no destinados a funciones policiales ni militares. Cabe preguntarse por la colaboración de civiles en estos hechos ${ }^{72}$.

Por otra parte, y como era de esperar, una de las grandes transformaciones que trajo el régimen de facto fue el cambio absoluto de administración en el COFOMAP. Se adoptaron medidas que terminaron con la participación de los trabajadores en el Consejo de administración, es más, fueron cooptando el acceso a servicios y canceladas las libertades civiles -como ocurría en todo el país por lo demás-, la empresa estatal continuó siéndolo, pero en un régimen absolutamente distinto, comenzando por la defenestración de todos los cargos de la empresa:

"1느os jefes de Direcciones, departamentos, Programas, Áreas, Predios, Secciones, al igual que los de Oficinas, Bodegas, Talleres y Canchas de depósito de madera, ubicadas en el área geográfica del Complejo, en su periferia u otros lugares de propiedad, posesión o tenencia de la empresa, deberán presentar renuncia formal, por escrito, a los cargos, puestos o funciones que desempeñan en la actualidad, sea cual fuere la calidad en que los ejercen". ${ }^{73}$

En este punto, es relevante señalar que el COFOMAP pasó a ser administrado por la Corporación Nacional Forestal (CONAF) una vez instalada la Junta Militar. Ya durante el desarrollo del régimen dictatorial, es interesante apuntar que a algunas mujeres se les empleó en viveros para la reforestación del bosque nativo de ese territorio. Ello se dio en el marco de los planes de absorción de empleo, dadas las altas cifras de cesantía que vivía el país y la zona. El hecho es muy recordado por los testimonios:

"yo antes que me casara ya trabajaba en CONAF... trabajábamos en forestación, cómo es que se llama esa cuestión, en los viveros, rescatábamos árboles de esos que daban semillas de árboles nativos, nosotros íbamos a hacer tablones así. Limpiarlos para que crezcan los árboles y ahí trabajamos harto tiempo, después me casé yo, me aparté de mis papás y seguí viviendo, aparte en el casino, también trabajé, seguí en CONAF, mis papás se salieron, cuando se salió toda la gente yo me quedé allá, porque allá quedó el mínimo, pero quedaron un par de personas no más" 74 .

Junto a esta primera ola de amedrentamientos y expulsiones, fueron pocas las familias que se quedaron trabajando en los predios. Fue a través del Programa de Empleo Mínimo (PEM)

\footnotetext{
72 Smart, Sebastián. 2019. La política del extractivismo: origen en dictadura y continuidad en democracia. En: Bohovslavsky, J, Fernández, K y Smart, S. (eds.) Complicidad económica con la dictadura chilena. Un país desigual a la fuerza, Santiago, LOM. Este texto trata la colaboración civil empresarial con las dictaduras del cono sur, sin duda es necesario profundizar en este tipo de situaciones para la montaña valdiviana y otras zonas del país.

${ }^{73}$ Archivo Corporación Raíces de Toledo. Resolución N 1, 19 de septiembre de 1973.

${ }^{74}$ Ester Retamal, comunicación personal, 22 de junio de 2019, Melefquén.
} 
que se mantuvo alguna actividad laboral, aunque en medio de una gran precariedad "porque el papá de mis hijos no quiso sacar casa, no quiso porque la gente se quedó ahí no más, no quiso salirse, se quedó ahí no más, pero solamente con el mínimo lo que le daba el gobierno no más"75.

Podemos señalar, sin temor a equivocarnos, que todos estos episodios y acciones fueron formas de violencia que pueden calificarse como vulneración de derechos, sumado a las graves violaciones a los derechos humanos ampliamente conocidas en la zona, todos estos dispositivos nos relatan la forma en que se instaló una política pensada y organizada por parte de la autoridad estatal con la firme intención de destruir las comunidades establecidas en la zona cordillerana. Puñir y Releco son clara muestra de esa política.

Llegados los años ochenta, la dictadura consolidó las llamadas reformas estructurales que dan el carácter neoliberal al derrotero ideológico del régimen de facto. En ese entendido el territorio y los habitantes que aún subsistían en el fundo tuvieron que hacer frente al proceso de capitalismo popular, ${ }^{76}$ método de expropiación por el cual los trabajadores pasaron a comprar acciones de sociedades que vinieron a reemplazar al COFOMAP, en palabras de algunos testimonios esto significó lo siguiente:

"A todas las casas pasaba él (mayordomo de montaña) a ofrecer acciones, a la gente, y la gente no quiso comprar acciones porque iban a pasar otro mes sin sueldo, entonces recorrimos, pasamos a Fuy y todas las casas ahí, pasamos a Río Chico y cuando veníamos de vuelta me dijo, oiga don Lalo, uta la gente que es tonta y yo como lo conocía casi de cabro chico le dije y ¿porque decís tú que la gente es tonta? me dio rabia, porque no compraron más acciones, cuando esas acciones se pagan, me dijo, con las otras acciones pagan esas, le dijiste alguna vez, a algunos, a presencia mía que se pagaban esas acciones, pucha yo sé eso y si fuera accionista me quedo con todas las acciones y eso es lo que van a hacer ustedes los empleados ahora" ${ }^{77}$.

De esta manera, el territorio se vio envuelto en prácticas de desposesión de los pocos recursos de los trabajadores de la zona. Las acciones fueron siendo compradas hasta concentrarse en pocas manos dejando la idea popular de este capitalismo en nada. Hoy en día, toda la propiedad del fundo Puñir-Releco está en manos de nuevos propietarios, ajenos a la

\footnotetext{
75 Ester Retamal, comunicación personal, 22 de junio de 2019, Melefquén.

${ }^{76}$ Huneeus, Carlos. 2005. El régimen de Pinochet. Santiago, Sudamericana, pp. 447-451. El capitalismo popular es explicado aquí como parte del proceso de privatizaciones, enmarcado en una estrategia nacional.

${ }^{77}$ Eduardo Sepúlveda, comunicación personal, 16 de agosto de 2019, Neltume.
} 
historia de los predios, como ocurrió también con otros fundos de la otrora empresa estatal ${ }^{78}$. Junto a ese proceso la zona se despobló, en una política de desplazamiento forzado de personas que ya trataremos en el último punto de este texto.

Cuando se produjo la licitación del fundo, la merma de los recursos existentes era conocida por los antiguos habitantes, aun así, el informe para realizar la privatización contaba lo siguiente: "En resumen, el predio posee un total de 49 unidades de galpones, bodegas, talleres, etc., que suman alrededor de 6.500 metros cuadrados y 45 unidades de casas de personal, administración y oficinas que alcanzan aproximadamente a 2.700 metros cuadrados. La mayor parte de las casas del personal se encuentran desocupadas"79. Durante décadas las tierras del fundo Puñir-Releco había logrado reunir, al menos, este patrimonio por la labor de sus trabajadores y familias, destacamos que el informe ya destaca la desocupación de las viviendas.

Un punto de inflexión definitivo para el fundo se vivió en 1983, en el marco de las privatizaciones que la dictadura emprendió por esos años. Así ocurrió por el proceso de venta de los predios Releco y Puñir, que en esa fecha fueron adquiridos por Juan Dazzarola Marchant, ${ }^{80}$ tras mantener la propiedad algunos años, para luego venderla a una sociedad denominada Inversiones Punta Chacana, lo que ocurrió en 1990. Finalmente, en 1991, los terrenos que comprenden el fundo forestal fueron comprados por quienes son los dueños hasta la actualidad, bajo la figura de la empresa Forestal S.A. La familia Luksic controla la propiedad de una extensión calculada en $20.519 \mathrm{~m}^{2} 81$.

De esta forma, las políticas neoliberales estuvieron presentes en el sector geográfico que nos ocupa, en orden sucesivo de aparición en la zona, por el capitalismo popular o pérdida patrimonial de los trabajadores, la desterritorialización de los asentamientos humanos, la reconversión productiva de la zona, enfocada a nuevos negocios ligados a la especulación financiera; en ello los negocios inmobiliarios y turísticos son los más relevantes, pero también lo es el surgimiento de nuevos agentes sociales y económicos ligados a los procesos anteriores. ${ }^{82}$

A continuación, revisaremos una de estas características, determinada por las formas completas del desplazamiento en este fundo, la forma más desconocida de violencia política y social contra esta población en plena instalación neoliberal.

\footnotetext{
78 Cámara de diputados. 2004. Informe de la comisión investigadora encargada de analizar presuntas irregularidades en las privatizaciones de empresas del Estado ocurridas con anterioridad al año 1990. Recuperado de: http://www.archivochile.com/Chile_actual/04_gob/chact_gob0013.pdf Consultado el 3 de diciembre de 2020. 79 ARNAD. Fondo COFOMAP, Volumen 136. "Bases de licitación pública". 19 de diciembre de 1982, s/p.

${ }^{80}$ Conservador de Bienes Raíces de Panguipulli. Inscripción N²60 Registro de Propiedad, 26 de mayo de 1983.

${ }^{81}$ Conservador de Bienes Raíces de Panguipulli. Inscripción N 46 Registro de Propiedad, 29 de enero de 1990.

82 De Matheus, Luis, et. al. 2018. El negocio de la conservación ambiental, pp. 22-23.
} 


\section{El duro final, desplazamiento forzado}

El proceso de desplazamiento forzado vivido en los predios de Puñir y Releco es compartido. Muchos poblados de la cordillera valdiviana, por no decir todos, lamentablemente, tuvieron un triste final. Recordado como los años de la expulsión de los antiguos habitantes, en un proceso tan desconocido como ignorado por las autoridades, considerado muchas veces como externalidad negativa del proceso privatizador que marcó la transformación del régimen de explotación del territorio. Ahora bien, el desplazamiento forzado es un delito de lesa humanidad que nos interesa conocer en el caso que relatamos, toda vez que es reconocido por la legislación internacional, muchas veces considerado por la situación del refugio en condiciones de conflictos internacionales; pues bien, también lo podemos reconocer al interior de los países:

"A los efectos de estos Principios, se entiende por desplazados internos las personas o grupos de personas que se han visto forzadas u obligadas a escapar o huir de su hogar o de su lugar de residencia habitual, en particular como resultado, o para evitar los efectos, de un conflicto armado, de situaciones de violencia generalizada, de violaciones de los derechos humanos o de catástrofes naturales o provocadas por el ser humano, y que no han cruzado una frontera estatal internacionalmente reconocida $" 83$.

De esta manera, el Derecho Internacional Humanitario viene proponiendo estas situaciones para las legislaciones que los países debieran respetar. Para nuestro caso y a nuestro juicio, los cambios en la política pública de las últimas décadas produjeron, cual catástrofe provocada por el ser humano, la expulsión o desplazamiento de miles de familias del territorio cordillerano, los siguientes párrafos nos hablan de estas situaciones.

Entre los amedrentamientos que podemos documentar en los predios estudiados, ya hacia fines de 1973 comenzaron a emitirse circulares por los nuevos directivos que limitaban actividades como las transacciones de animales por parte de los trabajadores, las que debían ser conocidas y autorizadas por el jefe de cada predio. Subrayamos esta situación con testimonios: "Todo movimiento de animales que se realice en el predio por compras y ventas que sean propiedad de los trabajadores, debe estar autorizado por el encargado de área que el departamento agropecuario tiene en la zona" ${ }^{84}$.

\footnotetext{
83 Naciones Unidas. Informe del Representante del Secretario General, Sr. Francis M. Deng, presentado con arreglo a la resolución 1997/39 de la Comisión de Derechos Humanos. 2, 11 de febrero de 1998. Recuperado de: https://www.acnur.org/fileadmin/Documentos/BDL/2001/0022.pdf Consultado el 3 de diciembre de 2020.

${ }^{84}$ Archivo Corporación Raíces de Toledo. 14 diciembre de 1973. comunicado del jefe del departamento agropecuario del Cofomap, Otto Heise, que amenaza con sanciones de no obedecer la orden.
} 
Acciones de este tipo, que se puede definir como políticas de despojo en el marco del terrorismo de Estado de inicios de la dictadura, fueron perjudicando lenta pero sistemáticamente las redes económicas que históricamente se habían constituido en las décadas anteriores. Respecto de aquello un testimonio recuerda un triste episodio: "a nosotros nos mataron a nuestros chanchos, entonces andaba un hombre recorriendo y yo le fui a preguntar porque lo había hecho y me dijo que nosotros teníamos que irnos, que no podíamos criar animales" 85 .

Cabe apuntar que, aunque desde comienzos de la dictadura se realizaron estas acciones de presión para la expulsión de las familias, fueron particularmente fuertes en la década de los ochenta, coincidiendo con el proceso privatizador y la imposición del capitalismo popular como estrategia de expulsión laboral. La animadversión hacia los trabajadores y sus familias se instaló sin reconocer su aporte de décadas a la incorporación de este territorio al Estado nacional; la desconfianza y la tristeza de los habitantes solo creció desde el momento del golpe militar y tuvo un final definitivo con la expulsión. Antes de esto hubo momentos de humillación que todos sufrieron en silencio.

En medio de la dictadura y con el fin de lograr que las familias forestales se fueran por su propia voluntad se procedió, como lo relata un ex habitante de Puñir, a sacar las familias. Como dijimos en la nota 55, en diciembre de 1976, el presidente del Consejo de administración del COFOMAP, Julio Ponce Lerou, hizo circular entre los trabajadores un atemorizante comunicado; los testimonios aseveran que aquello significó los primeros desplazamientos: "Cuando salió el gobierno de Pinocho (sic) al año, a los años empezaron a sacar gente" ${ }^{86}$. Según los testimonios recogidos, en algunos casos la expulsión se dio mediante avisos en formato de carta, los relatos explican que esta carta era leída en voz alta a las familias, pero no se entregó una copia a quienes eran los directamente afectados por esta política de despojo.

"A nosotros mismos casi se puede decir que nos corretearon, nos dieron un plazo no más, primero nos habían dado un plazo y yo busqué una parte pa' hacer una casita, pero después, eh, me dijeron no, por lo menos, no se saca ninguna gente más pa' afuera, ya po' me quedé ahí mismo no más, pero después ya, otra vez con la misma, por carta, ellos dejaban sus cartas por la oficina, ellos leían no más, tenían que irse no más y listo, como leerle la carta a otro uno. Todas las casas desarmadas, todos los vecinos alojando afuera, afuera con el frío" ${ }^{87}$.

\footnotetext{
85 Ester Retamal, comunicación personal, 22 de junio de 2019, Melefquén.

${ }^{86}$ Tránsita Guarda, comunicación personal, 21 de junio de 2019, Melefquén.

87 Segundo Andrade, comunicación personal, 21 de junio de 2019 Melefquén.
} 
Los procedimientos fueron, sin duda, irregulares, sin considerar planeación alguna como las conocidas erradicaciones en sectores urbanos durante la misma época. En esta zona las formas violentas predominaron, provocando total incertidumbre en el destino de las familias, sumado a la pérdida laboral que significaba salir del fundo. Además, los métodos de expulsión fueron confusos, como lo relata un testigo "... de la gente que se fue pa' Melefquén nosotros no veníamos, entonces se respetaba ese listado de gente que tenía que irse, entonces nosotros nos quedamos porque no veníamos, pero ahí fue duro porque mejor nos hubiésemos ido, a nosotros no nos dieron nada si aquí la casita que teníamos era una casita vieja y mala" ${ }^{88}$.

Pero habría que esperar hasta 1993 y 1994 para que los antiguos habitantes vivieran la expulsión definitiva tanto de sus trabajos, así como la pérdida de las viviendas de sus familias. De forma directa, mediante la reiteración de amenazas por parte de los nuevos administradores que obedecían a los nuevos patrones, pero también a través del uso de la fuerza pública, representada por carabineros, coadyuvantes en el amedrentamiento de cara a la expulsión definitiva de la población.

"Chuta ahí, ahí fue lo más triste porque imagínese nos echaron con carabineros, harto carabinero buta, si no hubiese sido que hubiesen andado dos, tres, pucha me acuerdo de las... que habían como cuatro cucas que nombrábamos nosotros antes, ahí habían de Choshuenco, de Neltume, de Liquiñe y de aquí del chancho, cuanto se llama, Pullinque y nosotros, va con un teniente que venía de Liquiñe ahí nos dieron camión para sacar las cositas, con un camión que tenía la empresa, un camión chico, tres cuartos, echamos todo ahí, irnos no más, no hallamos dónde irnos..." ${ }^{89}$.

En una historia que se cuenta sucesivamente por las diversas personas entrevistadas, la expulsión fue en extremo compleja. De esta manera, el desplazamiento forzado de quienes trabajaron y vivieron en la zona se realizó, en la mayor parte de los casos conocidos, mediante despidos, luego procedió el desarme de las casas, muchas veces ejecutado de manera inesperada y causando una gran impresión en toda la familia.

"Ahí fue sufrido si, oh, yo no me quería venir, es que jamás habíamos salido, nunca nos habíamos salido de ahí, toda una vida criados, nacidos ahí, toda una vida y llegar aquí donde era un puro hualve, [humedal] puro barro, tomábamos agua de los caballos, si, de primera fue muy sufrido, yo traía tanto niño chico, yo traía mi hija inválida, la que está allí, ella también la traía yo y era un sufrimiento de llegar y no tener ni agua limpia pa' tomar, ni un baño para ir, las casas desarmadas y no tenían techo, todas eran de tejuela, no había un

88 J. B., comunicación personal, 9 de agosto de 2019, Panguipulli.

89 J. B., comunicación personal, 9 de agosto de 2019, Panguipulli. 
techo como pa' ponerle a las casas, puros naylon y más encima en ese tiempo llovía, oh, fue terrible, mucho sufrimiento y sin trabajo los maridos más encima" ${ }^{90}$.

Por otra parte, y como se cuenta en este testimonio, muchas de esas viviendas fueron recuperadas en algunas de sus maderas que, junto a los contados enseres de cada familia fueron llevados a sectores alejados, fuera de los límites de los predios del fundo. Aun así, la precariedad fue la norma de ese traslado y el empobrecimiento de las familias, evidente. Las formas de erradicación de familias fueron bastante traumáticas y habituales en el período de clausura del fundo. Las experiencias urbanas son las más conocidas, a nuestro juicio también corresponden a desplazamientos forzados, aunque aquí se logran ver algunas políticas sociales, por supuesto acordes al neoliberalismo imperante ${ }^{91}$.

Con posterioridad a todo ese triste proceso se quemó todo lo que las familias dejaron en sus antiguas casas, ello con el objetivo último -según la opinión de muchas y muchos vecinosde que los antiguos habitantes constructores de la vida en la montaña no volvieran nunca más a sus viejos sectores, aceptando amargamente su expulsión: “Al final tuvieron que adaptarse a eso que ya, ya los habían echado de aquí, ya no había que vuelta darle y ahí ellos, como le dijera, como que se envejecieron más [los padres] es eso y ahora ya andan avanzados de edad ya y, como que se achacaron más"92.

Anexo a ello, la recepción y adaptación a los nuevos lugares de residencia no fue nada fácil: “la gente del pueblo, no nos querían que según que venía un piño de ladrones, que según que éramos ladrones, que nosotros les íbamos a robar las cosas... íbamos a comprar y nos miraban como bichos raros" ${ }^{93}$. Los relatos se suceden para explicar la estigmatización social de la población desplazada, redundando en pocas oportunidades laborales y las dificultades para incorporarse a una nueva comunidad.

Pero al caracterizar el proceso como desplazamiento debemos considerar algo más que la expulsión tan duramente vivida. En efecto, una gran cantidad de los ex habitantes del fundo Puñir-Releco, llegaron repentinamente a habitar una zona sin urbanizar y distante en la localidad de Melefquén, a las afueras de Panguipulli y de camino a Lanco, muy lejos de sus antiguas tierras. Por aquellos años el área de radicación correspondía a un sitio eriazo que obligó a los antiguos madereros a construir sus nuevas casas tras la traumática experiencia de su expulsión desde Puñir y Releco. Hoy un testigo reflexiona en relación con la expulsión: "Yo

\footnotetext{
90 Sonia Hernández, comunicación personal, 14 de agosto de 2019, Melefquén.

91 Valdivia, Verónica, et. al. 2012. La alcaldización de la política. Los municipios en la dictadura pinochetista, Santiago, LOM. Los alcaldes designados colaboraron con las de erradicaciones en las poblacionales de las grandes ciudades, proceso de desposesión de familias populares, pp. 125-138.

92 J. B., comunicación personal, 9 de agosto de 2019, Panguipulli.

${ }^{93}$ Sonia Hernández, comunicación personal, 14 de agosto de 2019, Melefquén.
} 
eso es lo que me da rabia e impotencia, porque es gente toda obrera, gente toda trabajadora que se sacó la murienta, gente honrada que se sacó la murienta trabajando y ¿cómo le pagaron? Por qué no fueron al último caso, no sé pu' una casa, algo digno donde llegar, no en el suelo" ${ }^{\prime 94}$.

Fig. 7. Últimas casas del fundo en ruinas, 2018.

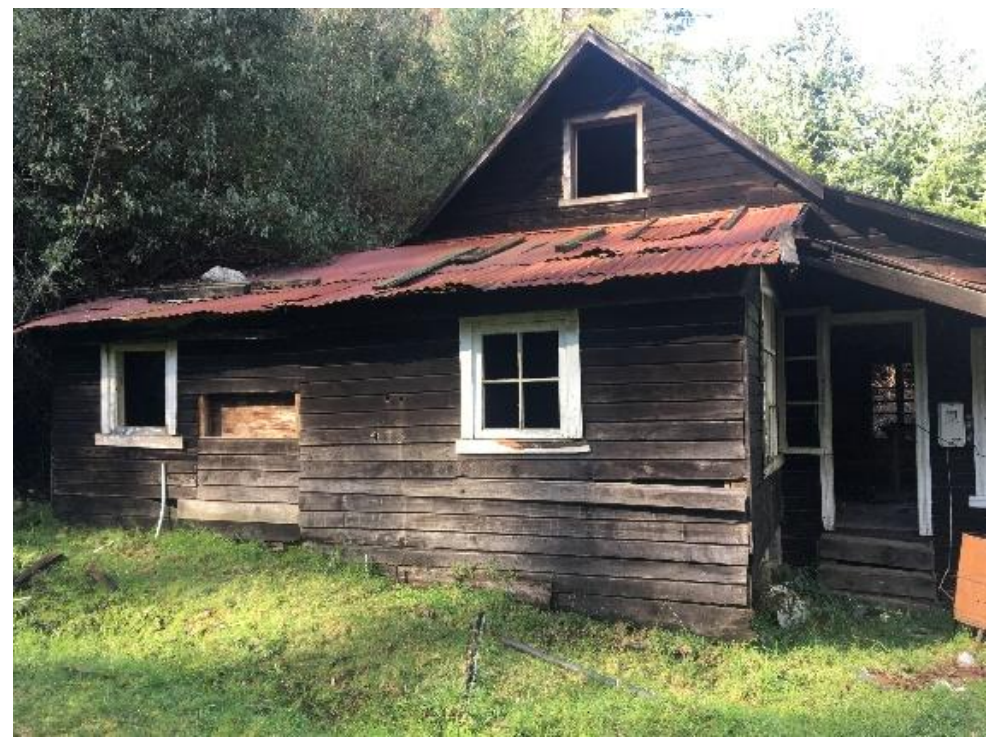

Fuente: Archivo Corporación Entre Lagos y Montañas

Para finalizar, la condición de expulsión y desplazamiento al que se vieron sometidas estas familias conllevó la pérdida de lazos sociales y comunitarios construidos durante décadas. Si bien un grupo pudo instalarse en las vegas de Melefquén, muchos otros partieron a diversas ciudades buscando trabajo, algunos otros emigrando hasta Argentina. Las condiciones laborales se restringieron en graves términos $y$, por otra parte, se produjo una pérdida patrimonial de suyo importante para las familias. Los relatos acerca de la imposibilidad de heredar nada a los hijos o ni siquiera entregarles posibilidades educativas habla de esa angustia paterna de la pérdida. Todo ello representa un daño enorme en las relaciones sociales y las formas de vida de estas familias, situación que podemos trasladar a la comunidad en su conjunto; ello significó su completa desaparición, dejando una tierra vacía donde antes se soñó y se produjo la vida.

Esta pérdida de relaciones sociales construidas en base al trabajo forestal durante décadas marca un nuevo momento histórico. Parte de las familias que siguieron ligadas a la zona

${ }^{94}$ Ester Retamal, comunicación personal, 22 de junio de 2019, Melefquén. 
debieron adaptarse a las nuevas formas neoliberales del trabajo. A modo de descripción, las relaciones sociales colaborativas de la era desarrollista dieron paso, mediante las políticas de despojo y desplazamiento, a relaciones signadas por el subcontrato y desterritorialización de los asentamientos humanos, características -entre otras- de la actual forma de explotación en el territorio.

Parte de ese recuerdo queda graficado en el estado actual en que se encuentra el acceso al fundo y algunas de las viejas viviendas, todas desocupadas y deterioradas, como se observa en las imágenes.

\section{Conclusiones}

Finalizando, hemos podido dar cuenta del valor histórico del fundo Puñir-Releco que, en primera instancia, corresponde a un espacio que reconoce el legado del pasado desarrollista propio del siglo XX. Pudimos observar diferentes muestras de la modernización que se estaba viviendo durante los años previos al golpe de Estado de 1973. Asimismo, la presencia de diferentes servicios y prestaciones que dotaron de un estilo de vida más urbanizado, aunque en el contexto de un área rural, lo entendemos como parte de la estrategia de prácticas paternalistas previas al COFOMAP y del proceso de movilización social de inicios de los setenta, todo ello moldeó la forma de vida y habitar que se llevó a cabo dentro del fundo hasta 1973.

Por otro lado, y a pesar de que los fundos de la cordillera valdiviana han dado cuenta de la existencia de pequeños conglomerados urbanos en el que habitaban las familias de los trabajadores de estas unidades productivas, estos conformaron verdaderos pueblos, como es el caso de Releco y Puñir, y con ello se constituyeron comunidades que, posteriormente, fueron desarraigadas de su estilo de vida, despojadas del territorio en el que múltiples generaciones vivieron parte importante de su vida, incluso habiendo muchas personas que nacieron en dichos lugares.

Así evidenciado el proceso examinado, podemos decir que la hipótesis de trabajo presentada es acertada, en tanto el régimen de prácticas paternalistas fue fundamental en la generación de una comunidad obrera que se sumó al proceso de transformaciones socialistas en el territorio, representado por el COFOMAP durante el periodo de la Unidad Popular, del mismo modo, también es cierto que la dictadura fundó unas nuevas relaciones sociales signadas por el neoliberalismo a través de políticas de despojo y represión hacia la población del territorio.

Por otra parte, hemos contribuido con datos acerca del desplazamiento forzado, proceso ocurrido sin mayores compensaciones económicas y que supuso un retroceso en el desarrollo, en el ascenso social, del que toda persona y/o familia tiene derecho a ser parte según los principios de la organización social y política tal como se entendía en la era desarrollista. 
Consideramos que el desplazamiento forzado es una clara muestra del proceso de transformaciones violentas en las relaciones sociales, evidenciado por la ausencia de Estado y, en el peor de los casos, la presencia castigadora de este por las violaciones a los derechos humanos. El desplazamiento nos ayuda a entender las maneras en que se presentan las transformaciones históricas de un territorio, teniendo al sujeto social como su protagonista que, inmerso en el proceso ideológico, vive en su propia carne las decisiones que el poder hegemónico decide, ejerce e impone.

Es importantes constatar que se reconoce un sentimiento de pertenencia que sigue existiendo en las personas que alguna vez habitaron Puñir y Releco, cuestión que se manifiesta en aspectos como los recuerdos que caracterizaron el devenir de la comunidad. La reflexión que nace luego de conocer los relatos y la información sobre este fundo nos llevan a pensar en la existencia de una comunidad que posee una trayectoria histórica, que se vio coartada por la expulsión de las familias que vivían en estas tierras. De esta manera, cabe señalar la existencia de una Corporación, "Entre lagos y montañas", que reúne a estas personas para proyectar su existencia y dar a conocer su contribución al desarrollo del territorio cordillerano, sin duda esto hace que la trayectoria de esta comunidad sea una historia presente.

Por último, la importancia histórica de fundos como Puñir-Releco se explica por reconocer una herencia, un patrimonio del periodo desarrollista, caracterizado por su referencia específica en el sur de Chile: la actividad maderera y agropecuaria, que desarrolló sus propias dinámicas. Al mismo tiempo, no se puede obviar la violación a los derechos humanos, así como los desplazamientos forzados y otros dispositivos sociales, económicos y políticos, todo ello como parte de la instalación del neoliberalismo; entonces, no es una cuestión solo de transformaciones económicas, conlleva una modificación radical en las relaciones sociales del territorio, su forma de habitar y la conflictividad que representa.

\section{Referencias citadas}

Acevedo, Pía y Rojas, Carlos. 2015. Enapinos. Los campamentos petroleros del fin del mundo. Santiago, El otro Kanon.

Alarcón, Natalia. 2018. “Usted entenderá en milímetros, yo entiendo en pulgadas: Educación rural en los fundos del territorio cordillerano de la provincia de Valdivia durante el periodo de la Reforma y Contra Reforma Agraria. (1960- 1990)", Universidad Austral de Chile, Valdivia, Tesis para optar al grado de Profesora de Historia y Ciencias Sociales.

Alfaro, Karen. 2016. "Acumulación por desposesión en Chile: El caso del Complejo Forestal y Maderero Panguipulli en el sur de Chile (1973-1990)”, en Historia 396, № 2, Valparaíso, pp. 229255. 
Artaza, Pablo. 2018. "La producción social del espacio salitrero tarapaqueño durante el ciclo de expansión: entre la necesidad patronal de control social y la resistencia de la sociedad pampina", en Tiempo histórico, $\mathrm{N}^{\circ} 17$, Santiago, pp. 47-84.

Barrena, José, Hernando, Maite y Rojas, Fernanda. 2016. “Antecedentes históricos sobre el Complejo Forestal y Maderero Panguipulli, provincia de Valdivia, Centro sur de Chile", en Bosque, Vol. 37 (N³), Valdivia, pp. 473-484.

Barrientos, Claudio. 2003. "Y las enormes trilladoras vinieron (...) a llevarse la calma: Neltume, Liquiñe y Chihuío, tres escenarios de la construcción cultural de la memoria y la violencia en el sur de Chile", en Del Pino, Ponciano y Jelin, Elizabeth (comps.) Luchas locales, comunidades $e$ identidades. Madrid, Siglo XXI, pp. 107-144.

Bernedo, Patricio. 1996. Panguipulli. Historia de cuatro tiempos, Santiago, s/editroial.

Bize, Cristóbal. 2017. El otoño de los raulíes. Poder popular en el Complejo Forestal y Maderero Panguipulli (Neltume, 1967-1973), Santiago, Tiempo Robado.

Bravo, José. 2012. De Carranco a Carrán, Las tomas que cambiaron la historia, Santiago, LOM.

Brito, Alejandra y Ganter, Rodrigo. 2015. "Cuerpos habitados, espacios modelados: el caso de la siderúrgica Huachipato, 1940-1970”, en Historia 396, N 1, Valparaíso, pp. 11-36.

Brito, Alejandra. 2018. "Memoria colectiva y construcción de territorio: auge y despojo de una cultura industrial. Los casos de la fábrica textil Bellavista-Tomé y la carbonífera Schwager en Coronel (1970-2007)”, en Izquierdas, Santiago, N42, pp. 1-29.

Cámara de diputados. 2004. Informe de la comisión investigadora encargada de analizar presuntas irregularidades en las privatizaciones de empresas del Estado ocurridas con anterioridad al año 1990. Disponible en: http://www.archivochile.com/Chile_actual/04_gob/chact_gob0013.pdf. (Consultado el 3 de diciembre de 2020).

Cardyn, Pedro. 2017. Sangre de baguales. Epopeyas mapuches y obreras en tiempos del Complejo Maderero Panguipulli. Un efecto mariposa inconcluso, Santiago, LOM.

Cofré, Víctor. 2019. Ponce Lerou. Pinochet. El litio. Las cascadas. Las platas políticas, Santiago, Catalonia.

CODEPU. 1991. Chile, recuerdos de la guerra. Valdivia, Neltume, Chihuío, Liquiñe, Santiago, Emisión. Comisión Nacional sobre Prisión Política y Tortura. 2005. Informe de la Comisión Nacional sobre Prisión Política y Tortura, Santiago, Ministerio del Interior.

De Matheus, Luis, Zunino, Hugo y Huiliñir-Curío, Viviana. 2018. "El negocio de la conservación ambiental: cómo la naturaleza se ha convertido en una nueva estrategia de acumulación capitalista en la zona andino-lacustre de Los Ríos, sur de Chile", en Scripta Nova, revista electrónica de geografía y ciencias sociales, Vol. 22 (N.583), Barcelona. Disponible en: https://revistes.ub.edu/index.php/ScriptaNova/article/view/19021/28907. (Consultado el 20 de abril de 2021).

Galilea O., Sergio, Leyton V., José, Ordóñez S., Fernando y Salamanca O., Fernando. 1972. “Agentes políticos y reestructuración del espacio y la producción en una región de Chile", en Revista EURE, Santiago, Vol. 2 (N.4), pp. 67-82. 
Gárate, Manuel. 2012. La revolución capitalista de Chile (1973-2003), Santiago, Ediciones Universidad Alberto Hurtado.

Goicovic, Igor. 2016. Trabajadores al poder. El movimiento de izquierda revolucionaria (MIR) y el proyecto revolucionario en Chile 1965-1994, Concepción, Escaparate.

Harvey, David. 2007. Breve historia del neoliberalismo, Madrid, Akal.

Huneeus, Carlos. 2005. El régimen de Pinochet, Santiago, Sudamericana.

Illanes, María A. 2003. Chile descentrado. Formación socio-cultural republicana y transición capitalista (1810-1910), Santiago, LOM.

Lefebvre, Henri. 2013. La producción del espacio, Madrid, Capitán Swing.

Marx, Karl. 1971. Elementos fundamentales para la crítica de la economía política (Borrador) 18571858, Madrid, Tomo I, Siglo XXI.

Morales, José Luis. 2020. Pan, tierra y socialismo. EI MIR en la precordillera de Valdivia 1967-1973, Concepción, Escaparate.

Naciones Unidas. 1998. Informe del Representante del Secretario General, Sr. Francis M. Deng, presentado con arreglo a la resolución 1997/39 de la Comisión de Derechos Humanos E/CN.4/1998/53/Add. 2, 11 de febrero de 1998 . Disponible en: https://www.acnur.org/fileadmin/Documentos/BDL/2001/0022.pdf (Consultado el 3 de diciembre de 2020).

Palieraki, Eugenia. 2014. i La revolución ya viene! EI MIR chileno en los años sesenta, Santiago, LOM.

Rivas, Ricardo. 2006. Desarrollo forestal de Neltume: Estado y trabajadores (1924-1990), Universidad Austral de Chile, Valdivia, Tesis para optar al título de Profesor de Historia, Geografía y educación Cívica.

Salazar, Gabriel. 2003. Historia de la acumulación capitalista en Chile: Apuntes de clase, Santiago, LOM.

Santana, Roberto. 2013. "Control del espacio y control social en el Estado militar chileno", en Revista de Geografía Espacios, vol. 3, N 6, Santiago, pp. 13-28.

Sierra, José. 1990. El obrero soñado. Ensayo sobre el paternalismo industrial. Asturias (1860-1917), Madrid, Siglo XXI.

Silva H., Robinson, Cortes E., Max, Cartes V., Luis, Angulo C., Carmen. 2020. Memorias expulsadas de Enco. Reconstrucción histórica de los antiguos habitantes del fundo Enco y su demanda de recuperación territorial. Disponible en: https://es.scribd.com/document/487126672/MemoriasExpulsadas. (Consultado 3 de diciembre de 2020).

Silva, Robinson. 2019. "Una forma de habitar en clave modernizadora. El barrio Arica de Valdivia, 1948-1960", en Sophia Austral, № 25, Punta Arenas, pp. 139-159.

Silva, Robinson. 2015. "Territorio en disputa: Guerrilla, represión y operativos cívico-militares en la precordillera valdiviana, Chile, 1981", en Boletín americanista, Barcelona, Año LXV, 2, N. 71, pp. 189-211. 
Smart, Sebastián. 2019. "La política del extractivismo: origen en dictadura y continuidad en democracia", en Bohovslavsky, Juan, Fernández, Karinna y Smart, Sebastián. (eds.), Complicidad económica con la dictadura chilena. Un país desigual a la fuerza, Santiago, LOM, pp. 161-175.

Sunkel, Osvaldo. 2011. El presente como historia. Dos siglos de cambio y frustración en Chile, Santiago, Catalonia.

Valdivia, Verónica, Álvarez, Rolando, Donoso, Karen. 2012. La alcaldización de la política. Los municipios en la dictadura pinochetista, Santiago, LOM.

Valdivia, Verónica. 2003. El golpe después del golpe. Leigh vs. Pinochet. Chile 1960-1980, Santiago, LOM.

Venegas, Hernán. 2014. "Paternalismo industrial y control social. Las experiencias disciplinadoras en la minería del carbón en Chile, Lota y Coronel en la primera mitad del siglo XX", en Les cahiers ALHIM, 28. Disponible en: https://journals.openedition.org/alhim/5099. (Consultado el 19 de abril de 2021).

Venegas, Hernán y Morales, Diego. 2015. "El despliegue del Paternalismo Industrial en la Compañía minera e industrial de Chile (1920-1940)", en Historia Crítica, № 58, Bogotá, pp. 117-136.

Videla, Enzo, Venegas, Hernán, Godoy, Milton. 2016. El orden fabril. Paternalismo industrial en la minería chilena 1900-1950, Valparaíso, América en Movimiento.

Wallerstein, Immanuel. 2014. El capitalismo histórico, Madrid, Siglo XXI.

\section{Entrevistas}

Silva Hidalgo, Robinson. 2019. Entrevista a Eduardo Sepúlveda, Neltume, 16 de agosto de 2019. Silva Hidalgo, Robinson. 2019. Entrevista a Ema Arias, Melefquén, 22 de junio de 2019. Silva Hidalgo, Robinson. 2019. Entrevista a Ester Retamal, Melefquén, 22 de junio de 2019. Silva Hidalgo, Robinson. 2019. Entrevista a Irma Álvarez, Melefquén, 10 de agosto de 2019. Silva Hidalgo, Robinson. 2019. Entrevista a J. B., Panguipulli, 9 de agosto de 2019. Silva Hidalgo, Robinson. 2019. Entrevista a Juan Vásquez, Panguipulli, 16 de agosto de 2019. Silva Hidalgo, Robinson. 2019. Entrevista a Martín Contreras, Panguipulli, 9 de agosto de 2019. Silva Hidalgo, Robinson. 2019. Entrevista a Segundo Andrade, Melefquén, 21 de junio de 2019 Silva Hidalgo, Robinson. 2019. Entrevista a Tránsita Guarda, Melefquén, 21 de junio de 2019. Silva Hidalgo, Robinson. 2019. Entrevista a Sonia Hernández, Melefquén, 14 de agosto de 2019. Silva Hidalgo, Robinson. 2019. Entrevista a Alen Vidal, Melfquén, 16 de agosto de 2019.

\section{Documentos}

Archivo Corporación Raíces de Toledo. 14 diciembre de 1973. Comunicación.

Archivo Corporación Raíces de Toledo. 10 de diciembre de 1976. "Memorando interno №10". ARNAD. Fondo COFOMAP. Breve síntesis del Complejo Forestal y Maderero (COFOMAP LTDA), Volumen 136. 8 de enero de 1974.

ARNAD. Fondo COFOMAP, "Bases de licitación pública”, Volumen 136. 19 de diciembre de 1982. 
Conservador de Bienes Raíces de Valdivia. Inscripción N 134 del Registro de Propiedad. 30 de diciembre de 1947.

Conservador de Bienes Raíces de Valdivia. Inscripción N¹338 del Registro de Propiedad. 4 de junio de 1954.

Conservador de Bienes Raíces de Panguipulli. Inscripción N² 260 del Registro de Propiedad. 26 de mayo de 1983.

Conservador de Bienes Raíces de Panguipulli. Inscripción Nº 46 del Registro de Propiedad. 29 de enero de 1990.

Diario de sesiones del Senado. 1972. Legislatura 316 ordinaria, p. 311.

Diario de sesiones del Senado. 1972. Legislatura 316 ordinaria, p. 313.

Diario Oficial de la República de Chile, 15 de marzo de 1971, p. 1014.

Diario Oficial de la República de Chile, 15 de octubre de 1971, p. 4141.

INFOR. 17 de enero de 1977. Complejo Forestal y Maderero Panguipulli, s/p.

ODEPLAN. Diciembre de 1972. "Programa de desarrollo social integrado para las provincias de Cautín, Valdivia y Osorno". Santiago de Chile, $65 \mathrm{p}$.

ODEPLAN. Enero de 1972. "Resumen del plan anual 1972". Serie VI, N 4, Santiago de Chile, $95 \mathrm{p}$. 